SAND99-0796

Unlimited Release

Printed July 1999

\title{
Aluminum-Enhanced Underwater Electrical Discharges For Steam Explosion Triggering
}

\author{
Lloyd S. Nelsona , Steve R. Hogeland $d^{b}$, and Thomas C. Roth \\ Reactor Safety Experiments Department \\ Sandia National Laboratories \\ P.O. Box 5800 \\ Albuquerque, New Mexico 87185-1139
}

\begin{abstract}
For a number of years, we have been initiating steam explosions of single drops of molten materials with pressure and flow (bubble growth) transients generated by discharging a capacitor bank through gold bridgewires placed underwater. Recent experimental and theoretical advances in the field of steam explosions, however, have made it important to substantially increase these relatively mild transients in water without using high explosives, if possible. To do this with the same capacitor bank, we have discharged similar energies through tiny strips of aluminum foil submerged in water. By replacing the gold wires with the aluminum strips, we were able to add the energy of the aluminum-water combustion to that normally deposited electrically by the bridgewire explosion in water.

The chemical enhancement of the explosive characteristics of the discharges was substantial: when the same electrical energies were discharged through the aluminum strips, peak pressures increased as much as 12-fold and maximum bubble volumes as much as 5 -fold above those generated with the gold wires. For given weights of aluminum, the magnitudes of both parameters appeared to exceed those produced by the underwater explosion of equivalent weights of high explosives.
\end{abstract}

\footnotetext{
${ }^{a}$ Member of Technical Staff, Sandia National Laboratories, when this work was performed; current address, Department of Engineering Physics, University of Wisconsin, Madison, WI 53706-1687.

bAssigned to Sandia National Laboratories by Ktech Corporation, Albuquerque, NM.
} 


\section{DISCLAIMER}

This report was prepared as an account of work sponsored by an agency of the United States Government. Neither the United States Government nor any agency thereof, nor any of their employees, make any warranty, express or implied, or assumes any legal liability or responsibility for the accuracy, completeness, or usefuiness of any information, apparatus, product, or process disclosed, or represents that its use would not infringe privately owned rights. Reference herein to any specific commercial product, process, or service by trade name, trademark, manufacturer, or otherwise does not necessarily constitute or imply its endorsement, recommendation, or favoring by the United States Government or any agency thereof. The views and opinions of authors expressed herein do not necessarily state or reflect those of the United States Government or any agency thereof. 


\section{DISCLAIMER}

Portions of this document may be illegible in electronic image products. Images are produced from the best available original document. 


\section{Acknowledgments}

We acknowledge the New Production Reactor Program at Sandia National Laboratories for support of these experiments. We are grateful to our colleagues S.E. Slezak, K.D. Bergeron, and K.O. Reil for their valuable suggestions throughout the course of the work. 


\section{Contents}

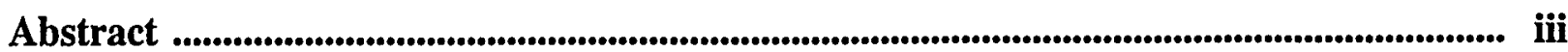

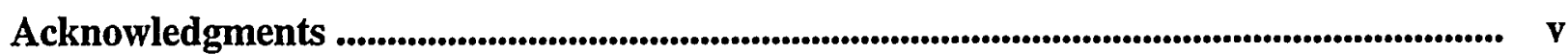

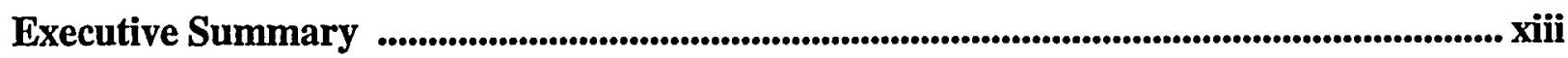

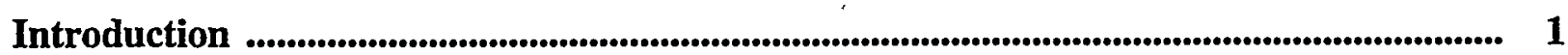

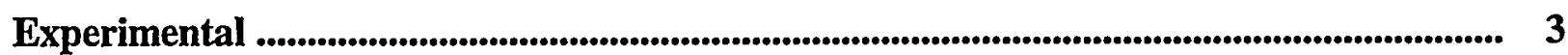

Underwater Explosion of Electrical Conductors ............................................................. 3

Tungsten .............................................................................................. 3

Aluminum ............................................................................................................ 3

Capacitor Discharge Unit ................................................................................................. 3

Pressure Transducers ..................................................................................... 5

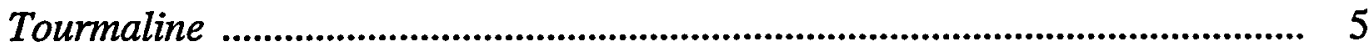

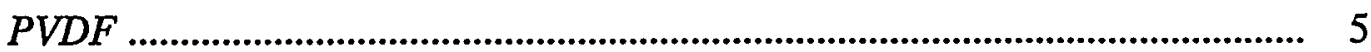

Current-Voltage Measurements ............................................................................................ 5

Water Chamber .............................................................................................................. 5

High-Speed Photography .................................................................................................... 6

Bubble Measurements ............................................................................................................ 6

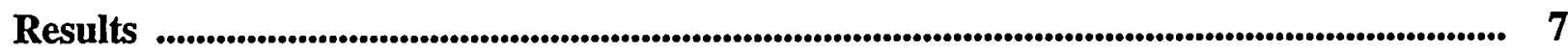

Preliminary Observations of Chemical Enhancement ..................................................... 7

Baseline Experiments ...................................................................................................... 7

Aluminum Enhancement of Bubble Growth .................................................................. 8

Thresholds for the $\mathrm{Al}+\mathrm{H}_{2} \mathrm{O}$ Chemical Reaction ................................................ 8

Aluminum Enhancement of the Discharges ........................................................ 8

Current-Voltage Behavior ...................................................................................................... 15

Recording of Pressure Transients Underwater ........................................................... 18

Aluminum Enhancement of Shockwaves ................................................................. 20

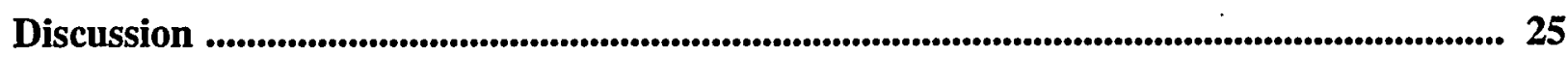

Comparisons with High Explosives ................................................................................ 25

Advantages of Aluminum Enhancement ........................................................................... 27

Triggering of Steam Explosions with Shockwaves ........................................................... 28

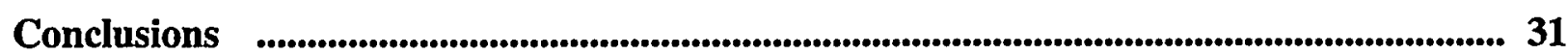

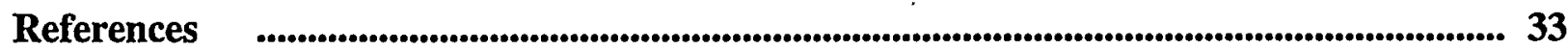

Appendix A. Correlation Between Maximum Bubble Volumes and

Bubble Growth Rates .................................................................................................................. 37 


\section{Figures}

$\underline{\text { Figure }}$

$\underline{\text { Page }}$

1. Photograph of the electrodes (at left) used for the underwater metallic conductor explosions and the two pressure transducers (at right) for measuring the shockwaves generated. The tourmaline transducer is contained in the vertical tubelike housing, while the PVDF transducer is mounted on the face of the thick cylindrical block. The electrodes are $1 \mathrm{~cm}$ apart and contain an aluminum strip in serpentine form.

2. Bubble volumes vs. time for six capacitor discharges through underwater tungsten wires $1 \mathrm{~cm}$ long. Energies and voltages of the discharges may be found in Table 1. .... 10

3. Bubble volumes vs. time for five capacitor discharges through underwater aluminum strips mounted between electrodes $1 \mathrm{~cm}$ apart. Weights of aluminum, energies and voltages that participate in the discharges may be found in Table 1.

4. Maximum bubble volumes produced by capacitor discharges through underwater aluminum strips and tungsten wires plotted against capacitor discharge energies. Experimental details may be found in Table 1.

5. Bubble energies generated by aluminum-water interactions vs. weight of aluminum strips ignited by underwater capacitor discharges. Energies have been corrected for the corresponding baseline water plasma bubble energies determined from Figure 4.

6. Current (lower with broad maximum) and voltage (with spike) traces produced when a $10 \mathrm{~mm}$-length of $0.0025 \mathrm{~mm}$-diameter tungsten wire was exploded underwater with a $1200 \mathrm{~J}$ capacitor discharge at $4 \mathrm{kV}(42-34-2)$.

7. Current (lower) and voltage (upper, with spike) traces produced when a $32 \mathrm{~mm}$-length of $2 \mathrm{~mm} \times 0.13 \mathrm{~mm}$ strip of aluminum foil ( $21.6 \mathrm{mg}$ ) was exploded underwater with a $1200 \mathrm{~J}, 4 \mathrm{kV}$ capacitor discharge (42-30-3).

8. Pressure traces recorded at $103 \mathrm{~mm}$ with a PVDF (upper) and a tourmaline (lower) transducer produced by the underwater explosion of a $21.6 \mathrm{mg}$ strip of aluminum foil. (Current and voltage traces for this experiment are shown in Figure 7.) (42-30-3).

9. Comparison of pressure traces produced with a PVDF transducer at $103 \mathrm{~mm}$ by the underwater discharge of $1200 \mathrm{~J}$ at $4 \mathrm{kV}$ through a $21.6 \mathrm{mg}$ strip of aluminum (upper) and a $10 \mathrm{~mm}$-length of $0.025 \mathrm{~mm}$ tungsten wire (lower). The difference between the shock arrival times at the transducer is caused by the approximately $30 \mu$ s required to heat the aluminum to the ignition

temperature as indicated by comparing Figures 6 and 7. (42-30-3, 42-34-2). 


\section{Figures (Concluded)}

Figure

Page

10. Peak pressures recorded at $103 \mathrm{~mm}$ with a PVDF transducer, produced when strips of aluminum foil or tungsten wires were exploded underwater with various discharge energies. Experimental details may be found in Table 1.

11. Enhancements of peak pressures (upper plot) and maximum bubble volumes (lower plot) achieved by replacing fine tungsten wires with aluminum strips between electrodes and discharging the same electrical energies through them. Data are taken from Figures 11 and 4, respectively. Experimental details may be found in Table 1.

12. Comparison of the bubble volumes as a function of time produced by the underwater discharge of $1200 \mathrm{~J}$ at $4 \mathrm{kV}$ through a $21.6 \mathrm{mg}$ strip of aluminum foil (upper) and a $10 \mathrm{~mm}$-length of $0.0025 \mathrm{~mm}$ tungsten wire (lower) (42-303, 42-34-2). See Table 1 for experimental details. Horizontal line indicates the maximum volume of a bubble produced by the underwater explosion of a commercial detonator that contains $64 \mathrm{mg}$ of high explosive.

A-1. Maximum bubble volumes plotted against the corresponding slope of the bubble volume-time curve for various bubbles generated by discharging capacitors through underwater aluminum strips. See Table 1 for experimental details. 


\section{Tables}

Table

Page

1. Experimental Parameters for Underwater Explosions of Aluminum Strips and Tungsten Wires Initiated by Capacitor Discharges

2. Comparison of Underwater Aluminum-Enhanced Capacitor Discharge with Two Commercial Detonators Exploded Under Water 


\section{Executive Summary}

To produce stronger pressure transients and bubble growths in water for steam explosion triggering without using very large power sources or high explosives, we have investigated the underwater electrical explosions of aluminum strips that react chemically with the surrounding water. We found that identical capacitor discharges passed through aluminum conductors can produce as much as a 12-fold increase in the peak pressures and about a 5-fold increase in maximum bubble volumes above those produced by the nonchemical electrical breakdown between the same submerged electrodes. Thus, we were able to increase the maximum capability of our capacitor bank to produce these transients in water by an order of magnitude for use in a variety of steam explosion triggering applications.

To produce these energetic aluminum explosions, it is necessary to discharge sufficient energy to raise the aluminum strip to an ignition temperature well above the melting point. We found a threshold of about $24 \mathrm{~J} / \mathrm{mg}$ of aluminum below which the metal simply parted by partial melting. But as the discharge energy was increased above this threshold, energetic metal-water chemical reactions began to set in that were accompanied increasingly by the emission of light. To assure complete combustion of the metal in our experiments, we discharged about $55 \mathrm{~J} / \mathrm{mg}$ through each strip.

The maximum bubble volumes produced by our exploding aluminum strips achieved pressure-volume (PV) energies (work done by the expanded bubble) as high as about $14 \mathrm{~J} / \mathrm{mg}$ of aluminum for our most energetic bubble. These energies are approaching the thermodynamic limit of about $17 \mathrm{~J} / \mathrm{mg}$ for the aluminum-water reaction and are considerably larger than the corresponding PV energies of about $4 \mathrm{~J} / \mathrm{mg}$ achieved by the underwater detonation of high explosives. Moreover, it is also possible to achieve detonations with amounts of aluminum as small as about $7 \mathrm{mg}$, far below the minimum masses of high explosives with which detonations can be achieved.

Compared to the use of high explosives in the laboratory, the use of aluminum-water explosions offers many advantages such as low cost, easy availability, safety in transit and storage, and the avoidance of the many administrative, construction, personnel, and good neighbor requirements often mandated in the use of high explosives. 


\section{Introduction}

Steam explosions sometimes occur when a hot molten material contacts liquid water. Even though these explosions have the potential to cause serious accidents in the metals, nuclear and other industries, they are not well understood. In order to provide information about the nature, energetics, and possible suppression of these explosions, many experiments have been performed in which both large and small quantities of molten materials have been brought together with liquid water in various configurations (see reviews by Buxton and Nelson 1975; Cronenberg and Benz 1980; Reid 1983; Corradini et al. 1988).

The release of single drops of melt into water has provided an important experimental configuration for the study of steam explosions because of the low cost, safety, and ability to provide high-quality diagnostics during and after the experiments. Moreover, single drop experiments can provide quantitative inputs for the development and validation of theories to predict the effects of full-scale steam explosions and thus reduce the need for more costly, hazardous, and often difficult-to-interpret experiments with large amounts of melt. Although single drops of some molten materials explode spontaneously when released into water (for example, Sn, Pb, Bi (Flory et al. 1969; Dullforce et al. 1976; Shoji and Takagi 1983)), drops of a number of other melts do not (for example, Al, Al-Li alloys, Fe (Nelson et al. 1989; Nelson and Duda 1982; Nelson et al. 1994)), even though the temperatures of both melt and water may lie in the same ranges. When the molten globules do not explode spontaneously, explosions in many cases can be initiated by introducing pressure disturbances into the water.

Several schemes have been used for producing pressure transients in water for steam explosion triggering. These include the use of shock tubes (Sharon and Bankoff 1981), mechanical impact (Peppler and Till 1986; Kim and Corradini 1986; Epstein and Miller 1987), underwater electrical discharges (Anderson and Armstrong 1981; Arakeri et al. 1978; Nelson and Duda 1981, 1982, 1985; Kondo et al. 1979;.Ciccarelli 1991), and the detonation of small amounts of high explosives (Beck et al. 1991; Ciccarelli 1991).

In a number of earlier studies, we used underwater electrical discharges through commercial gold bridgewires to initiate explosions of single drops of several melts falling freely through water (Nelson and Duda 1981, 1982, 1985; Nelson et al. 1992; Nelson 1995). The exploding bridgewire procedure is relatively safe to use in the laboratory. It is also reproducible, readily synchronized with other events and, by varying the capacitor discharge circuit and the distance between the melt drop and bridgewire, one can expose the drops to transients with various peak pressures up to several megapascals (Nelson et al. 1994).

To understand how single drop experiments might relate to the triggering and propagation of steam explosions of large amounts of melt, we began to investigate the effects of increasing the peak pressure of the triggering transients. Our first approach was to explode the bridgewire at the inner-focus of a submerged semiellipsoidal reflector (Chaussy et al. 1986) as the drop of melt fell through the outer focus. Although we were able to increase the peak pressure produced at the drop about 20-fold, we observed a disappointing ineffectiveness of the transient to trigger the steam explosions of both molten thermite-generated iron-alumina drops (Nelson et al. 1992) and drops of molten aluminum (Nelson 1995) compared to those exposed to bridgewires fired 
identically at the same distance without the reflector. We hypothesized that perhaps the conically focused shockwaves generated with the reflector were unable to destabilize film boiling around a hot drop as effectively as less intense shockwaves radiating spherically outward from a small source, such as an unconfined bridgewire explosion (Nelson et al. 1992; Nelson 1995).

To test this hypothesis, we tried to increase the peak pressure by discharging the capacitors through the gold bridgewires at higher voltages. We found, however, that when the discharge voltage was increased 10 -fold (for example, from $1.9 \mathrm{kV}$ to $19 \mathrm{kV}$ while holding the discharge energy constant at $282 \mathrm{~J}$ ), the peak pressure at the drop only doubled (Nelson et al. 1994).

To achieve still higher peak pressures with spherically radiating shockwaves, we turned to the chemical enhancement of the discharge by substituting tiny aluminum strips for the gold bridgewires; this follows earlier work by Lee and Ford 1988a, b. By superimposing the energetic aluminum-water reaction on the mostly electrical arcing through water vapor produced during the nonchemical gold bridgewire explosion, we were able to increase the peak shockwave pressures at a given location by more than an order of magnitude. Moreover, by measuring the volumes of the bubbles that grew during the enhanced underwater discharges, we learned that the aluminum-water combustion reaction could release almost as much as the thermodynamically predicted energy, $17.1 \mathrm{~J} / \mathrm{mg}$ of aluminum, which is more than four times that predicted for equivalent weights of conventional high explosives (Rightley et al. 1993). 


\section{Experimental}

\section{Underwater Explosions of Metal Conductors}

To appropriately assess the effects of chemical enhancement, we discharged capacitors at high voltage through small weights of both fine tungsten wire and aluminum strips connected between electrodes $1 \mathrm{~cm}$ apart that were submerged $15 \mathrm{~cm}$ beneath the surface of the water. We substituted tungsten for the gold wires because both metals have negligible energies of chemical reaction with water, the stronger tungsten wire can be easily mounted between the electrodes, and the tungsten is less expensive.

\section{Tungsten}

To provide baseline information about the simple water plasmas produced by the gold bridgewire discharges studied previously (Nelson et al. 1994), we stretched single strands of $0.0025 \mathrm{~mm}$ tungsten wire between the electrodes. The main purpose of both the fine gold wire in the bridgewire assembly and the fine tungsten wire used here is to produce a well-defined and reproducible breakdown path in the water between the electrical connectors.

\section{Aluminum}

To chemically enhance the underwater discharges, we placed strips of Type 5052 aluminum foil between the same pair of electrodes. The foil was $0.127 \mathrm{~mm}$ thick, cut into strips $2 \mathrm{~mm}$ wide. Each strip was cut longer than required, preweighed, and bent into an appropriate serpentine form $1 \mathrm{~cm}$ in length. It was then clamped between the electrodes at the proper locations along the strip to expose a known weight of metal to the discharge. After each discharge, the ends of the strip that remained in the clamps were recovered and weighed to determine by difference the amount of metal that had participated in the interaction. A photograph of a clamped serpentine strip is shown in Figure 1. We used relatively closely spaced electrodes $(1 \mathrm{~cm}$ apart) to produce as compact a discharge as possible to generate essentially spherically radiating shockwaves (cf. Lee and Ford 1988b, who used much longer aluminum wires in their studies).

\section{Capacitor Discharge Unit}

The capacitor discharge unit was used in previous studies (Nelson et al. 1994). It can operate up to a maximum voltage of $4 \mathrm{kV}$ and contains six capacitors of $25 \mu \mathrm{F}$ each. The discharge was switched with an EG\&G Corporation (Salem, MA) Type GP30B triggered spark gap with a rated minimum switching voltage of $2 \mathrm{kV}$. The spark gap was triggered with an EG\&G Corporation Type TM11A trigger module. Thus, the power unit could produce discharges at voltages over the range of $2 \mathrm{kV}$ to $4 \mathrm{kV}$. By using from one to six capacitors in this range of voltages, we were able to discharge electrical energies between $50 \mathrm{~J}$ and $1200 \mathrm{~J}$ through the metallic conductors. 


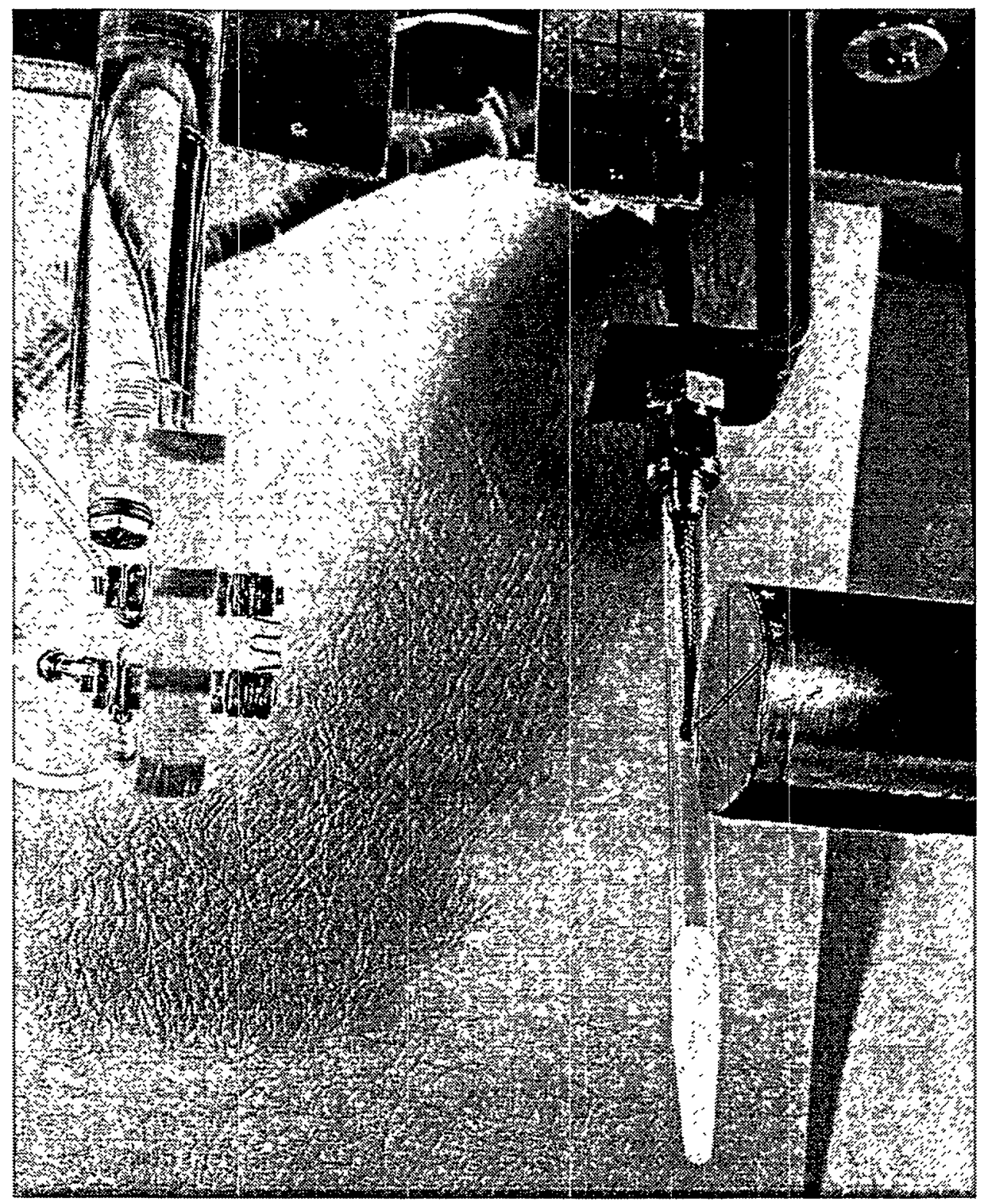

Figure 1. Photograph of the electrodes (at left) used for the underwater metallic conductor explosions and the two pressure transducers (at right) for measuring the shockwaves generated. The tourmaline transducer is contained in the vertical tubelike housing, while the PVDF transducer is mounted on the face of the thick cylindrical block. The electrodes are $1 \mathrm{~cm}$ apart and contain an aluminum strip in serpentine form. 


\section{Pressure Transducers}

Two types of pressure transducers were used in this work.

\section{Tourmaline}

The Type 128A01 tourmaline underwater blast transducer was obtained from PCB Piezotronics (Depew, NY). The active element of this transducer is a tourmaline crystal disc $0.76 \mathrm{~mm}$ thick $X$ $3.8 \mathrm{~mm}$ O.D. suspended in an oil-filled polymeric tube. Its leads pass into a built-in preamplifier about $5 \mathrm{~cm}$ from the element. This type of transducer has been used extensively in underwater shockwave experiments (see Lee and Ford 1988b).

\section{PVDF}

A Type Kp122B polyvinylidene fluoride (PVDF) pressure transducer was obtained from Ktech Corporation (Albuquerque, NM). Its pressure element is $100 \mu \mathrm{m}$ thick and has an active area of $4 \mathrm{~mm}^{2}$. The construction and performance of this type of transducer in water have been described by Hyndman and Gaffney 1989 and Johnson et al. 1993.

Both the PVDF and the tourmaline transducers were placed in the water side by side, $103 \mathrm{~mm}$ horizontally from the center point of the electrodes as shown in Figure 1. The signals from both transducers were recorded with a Le Croy (Chestnut Ridge, NY) Model 9450A dual channel 400 $\mathrm{MHz}$ digital recording oscilloscope.

\section{Current and Voltage Measurements}

In a manner similar to Lee and Ford $1988 \mathrm{a}, \mathrm{b}$ and Lee 1991, we measured the transient current and voltage produced during each capacitor discharge. This was done with a calibrated voltage dividing resistor and a Pierson coil, respectively. Recording was done with a second LeCroy oscilloscope of the type described in the previous section.

\section{Water Chamber}

The experiments were performed in an open upright cylindrical chamber made of $9.5-\mathrm{mm}$-thick Type 304 stainless steel. The inside diameter of the flanged open top was $0.94 \mathrm{~m}$ and the depth along the vertical axis to the rounded bottom was $0.72 \mathrm{~m}$. It was filled to the brim with deionized water at room temperature (nominally $298 \mathrm{~K}$ ). The chamber wall had several $13 \mathrm{~cm}$ diameter ports. For photography, we used a port with horizontal axis $18 \mathrm{~cm}$ below the upper edge of the chamber. It was fitted with a window made from $32 \mathrm{~mm}$-thick optical grade Lexan (Zelux). The electrodes, the exploding metal, and the transducers were hung in the water beneath beams that rested across the upper flanged edge of the chamber.

The dimensions of our water chamber were approximately the same as the chamber used by Lee and Ford 1988b, permitting direct comparisons with their results. 


\section{High-Speed Photography}

The primary diagnostic for studying the bubbles produced by the underwater discharges was high-speed photography of the explosions. This was accomplished with a Hycam (Redlake Corporation, Morgan Hill, CA) 16-mm framing camera operated at about 6000 frames per second. Photographic illumination was provided by four submersible Type Q13000 $1 \mathrm{~kW}$ quartzhalogen photographic lamps (Amron International, Escondido, CA) placed in pairs inside the chamber at either side of the window. Appropriate distance and time fiducials were placed on each frame of film during the photography.

\section{Bubble Measurements}

The volumes and the rates at which the discharge-generated bubbles grew and collapsed were determined from the 16-mm high-speed films and their fiducial calibrations. Selected frames from the films were analyzed with a Jandel (Corte Madera, CA) JAVA automatic digitizing video analysis system applied to frame-by-frame hand tracings of projected film images. Bubble volumes were estimated by assuming that each image could be represented as the sum of many horizontal right circular cylindrical slices with the diameters measured from the bubble images at all positions along the vertical axis.

If the photographic images were partially obscured, the maximum bubble volumes often could be estimated with the procedure outlined in Appendix A. 


\section{Results}

\section{Preliminary Observations of Chemical Enhancement}

Our interest in chemical enhancement of underwater electrical discharges originated with the occasional use of the so-called "penciled" bridgewire during test sequences with gold bridgewires. Because of the inconvenience and cost of replacing a previously used ("burned out") bridgewire assembly, we sometimes restored the conducting path between the electrical leads by making a mark with a soft pencil on the plastic face of the bridgewire where the gold wire previously had been (see Nelson et al. 1994, for a photograph of a fresh bridgewire). This procedure provides a quick and easy way to produce another bridgewire explosion for qualitative checks of circuitry, photographic exposures, sequencing, positioning and alignment, and so on. The "penciling" and explosions may be repeated several times on a given bridgewire assembly if necessary.

In situations where the "penciled" bridgewires were placed underwater, the effects of the discharges always seemed somewhat more vigorous than when the discharge passed through a fresh gold bridgewire under similar conditions. This was confirmed when we took high-speed photographs of underwater discharges through "penciled" bridgewires (Nelson et al. 1994). Although not highly reproducible, the bubble images were always larger (i.e., showed larger PV energies) than the bubble images produced by fresh gold bridgewires with identical electrical discharge energies. We concluded that combustion of the graphite from the pencil mark in water added chemical energy to that of the water plasma generated by the electrical discharge through a gold bridgewire.

Because of our interest in underwater aluminum combustion, for example, ignition-type steam explosions (Nelson et al. 1995; Nelson 1995), we then looked at enhancing the vigor of our discharges with small amounts of aluminum substituted for the graphite of the "penciled" bridgewires. Our first approach (Nelson et al. 1994) was to tape or cement tiny pieces of aluminum foil over new gold bridgewires. We saw enhancement of bubble volumes analogous to those of the "penciled" bridgewires when the aluminum strips had been ignited by the adjacent bridgewire discharge. Unfortunately, the amount of aluminum that can be ignited in proximity to a gold bridgewire discharge is limited because of the small dimensions of the assembly (see Nelson et al. 1994).

Next, we turned to mounting strips of aluminum foil directly between underwater electrodes $1 \mathrm{~cm}$ apart. This procedure was roughly equivalent to that used by Lee and Ford 1988a, b to heat and ignite aluminum wires placed between electrodes several centimeters apart. We used this procedure for the rest of the experiments reported here.

\section{Baseline Experiments}

To provide a baseline for studying only the electrical arcing, we placed filaments of fine tungsten wire between the $1 \mathrm{~cm}$-apart underwater electrodes. The diameter of this wire was $0.0025 \mathrm{~mm}$ 
( 2.5 microns, $0.1 \mathrm{mil}$ ). The fine wire provided a reliable breakdown path through the water with negligible mass of a metal that also has negligible energy of combustion. The chemical effects here are thus assumed to be essentially zero. We performed discharges at a series of electrical energies and recorded the current, voltage traces, peak pressures, $\Delta \mathrm{p}$, and the times, $\mathrm{t}_{\max }$, to achieve the maximum bubble volumes, $V_{\max }$. The conditions for the baseline experiments are summarized in Table 1.

The growth and collapse of the baseline bubbles generated at various capacitor discharge energies are shown in Figure 2. This figure shows bubble volumes as a function of time that were produced as the capacitor discharge energies were progressively increased from $423 \mathrm{~J}$ to $1200 \mathrm{~J}$ with voltages of either $3.36 \mathrm{kV}$ or $4.0 \mathrm{kV}$, as indicated in Table 1.

\section{Aluminum Enhancement of Bubble Growth}

\section{Thresholds for the $\mathrm{Al}+\mathrm{H}_{2} \mathrm{O}$ Chemical Reaction}

Following Lee and Ford 1988a, b further, we also looked at the energy thresholds needed to initiate the chemical interactions of our aluminum strips with water. We found that discharge energies greater than about $24 \mathrm{~J} / \mathrm{mg}$ were required to initiate mild chemical interactions. Our thresholds are higher than those of about $10 \mathrm{~J} / \mathrm{mg}$ observed by Lee and Ford with relatively long aluminum wires. Perhaps the geometry of the wire versus the strips or the differences between the alloys accounted for the disparities in the thresholds between our work and the work of Lee and Ford.

We obtained the distinctly vigorous explosions of the aluminum-water combustion, however, only when the energy discharged exceeded about $35 \mathrm{~J} / \mathrm{mg}$. Therefore, in subsequent portions of our work, we deliberately overdrove our strips to ensure complete combustion of the aluminum with the water. Therefore, we normally used discharge energies in the range of 40 to $58 \mathrm{~J} / \mathrm{mg}$, usually at the higher energy end of this range. There is some uncertainty in targeting these energy values because variations in clamping cause variations in the lengths of the aluminum strips that participate in a given discharge. The exact weights of the metal that burned are not known until after the experiments, when the pieces of unburned metal are retrieved from the electrodes and weighed.

\section{Aluminum Enhancement of the Discharges}

We produced a set of plots of bubble growth and collapse versus time corresponding to the baseline plots in Figure 2 by discharging comparable energies through strips of aluminum with progressively increasing weights. We held the energy discharged per weight of metal constant at approximately $55 \mathrm{~J} / \mathrm{mg}$ of aluminum. Five aluminum-water experiments were performed that resulted in vigorous combustion-generated bubbles; the data are presented in Table 1 . These plots are shown in Figure 3. Note that the chemical enhancement with the aluminum strips produced bubbles with maximum volumes greater than 4 liters, as shown in Figure 3 . The maximum bubble volumes produced at the same discharge energies without the chemical enhancement were always less than 1 liter, as shown in Figure 2. 
Table 1. Experimental Parameters for Underwater Explosions of Aluminum Strips and Tungsten Wires Initiated by Capacitor Discharges

\begin{tabular}{|c|c|c|c|c|c|c|c|c|c|}
\hline \multirow[b]{2}{*}{ Expt. No. } & \multirow[b]{2}{*}{ Metal } & \multirow{2}{*}{$\begin{array}{c}\text { Metal } \\
\text { Weight } \\
\text { (mg) }\end{array}$} & \multicolumn{3}{|c|}{ Electrical Discharge } & \multicolumn{2}{|l|}{ Specific } & & \multirow{2}{*}{$\begin{array}{c}\Delta \mathrm{p} \\
\mathrm{PVDF}^{\mathrm{b}} \\
(\mathrm{MPa})\end{array}$} \\
\hline & & & $\begin{array}{c}\text { Capacitance } \\
(\mu F)\end{array}$ & $\begin{array}{c}\text { Voltage } \\
(\mathrm{kV})\end{array}$ & $\begin{array}{l}\text { Energy } \\
\text { (J) }\end{array}$ & $\begin{array}{l}\text { Energy } \\
(\mathrm{J} / \mathrm{mg})\end{array}$ & $\begin{array}{l}\mathrm{t}_{\max } \\
(\mathrm{ms})\end{array}$ & $\begin{array}{l}V_{\max ^{\mathrm{a}}} \\
\left(\mathrm{cm}^{3}\right)\end{array}$ & \\
\hline $42-32-1$ & $\mathrm{Al}$ & 7.6 & 75 & 3.36 & 423 & 55.7 & 5.6 & 885 & 4.7 \\
\hline $43-33-1$ & $\mathrm{Al}$ & 10.4 & 100 & 3.36 & 564 & 54.3 & 7.0 & 1595 & 14.1 \\
\hline $42-30-1$ & $\mathrm{Al}$ & 14.43 & 100 & 4.00 & 800 & 55.4 & 8.2 & 2909 & 16.8 \\
\hline $42-30-2$ & $\mathrm{Al}$ & 17.32 & 125 & 4.00 & 1000 & 57.7 & 8.2 & 3280 & 19.6 \\
\hline $42-30-3$ & $\mathrm{Al}$ & 21.64 & 150 & 4.00 & 1200 & 55.5 & 9.5 & 4350 & 26.5 \\
\hline $42-34-4$ & W & 0.0098 & 75 & 3.36 & 423 & 4326 & 5.0 & 454 & 1.53 \\
\hline $42-29-1$ & W & 0.0098 & 100 & 3.36 & 564 & 5767 & 6.7 & 646 & 0.094 \\
\hline $42-33-3$ & W & 0.0098 & 100 & 3.36 & 564 & 5767 & 5.0 & 519 & 1.35 \\
\hline $42-34-1$ & W & 0.0098 & 100 & 4.00 & 800 & 8181 & 5.5 & 921 & 1.43 \\
\hline $42-34-3$ & W & 0.0098 & 125 & 4.00 & 1000 & 10226 & 5.5 & 789 & 2.13 \\
\hline $42-34-2$ & w & 0.0098 & 152 & 4.00 & 1200 & 12271 & 5.5 & 874 & 2.13 \\
\hline
\end{tabular}

${ }^{a}$ Volumes measured at local atmospheric pressure, $\mathrm{P}_{\mathrm{atm}}=0.085 \mathrm{MPa}$.

${ }^{b}$ Recorded at a distance of $103 \mathrm{~mm}$. 


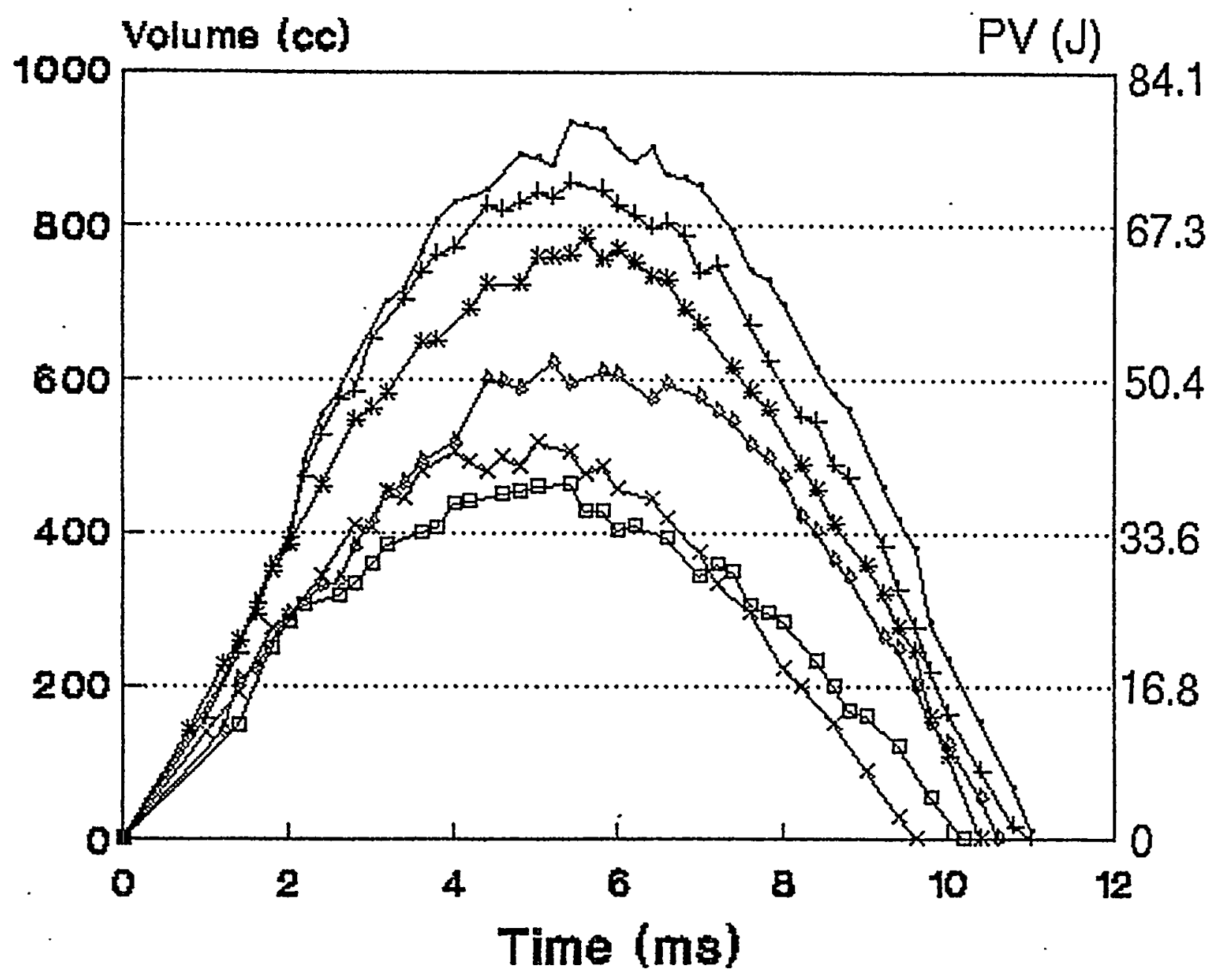

Figure 2. Bubble volumes vs. time for six capacitor discharges through underwater tungsten wires $1 \mathrm{~cm}$ long. Energies and voltages of the discharges may be found in Table 1 .

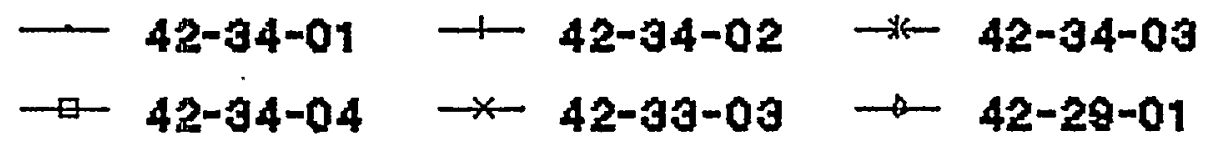




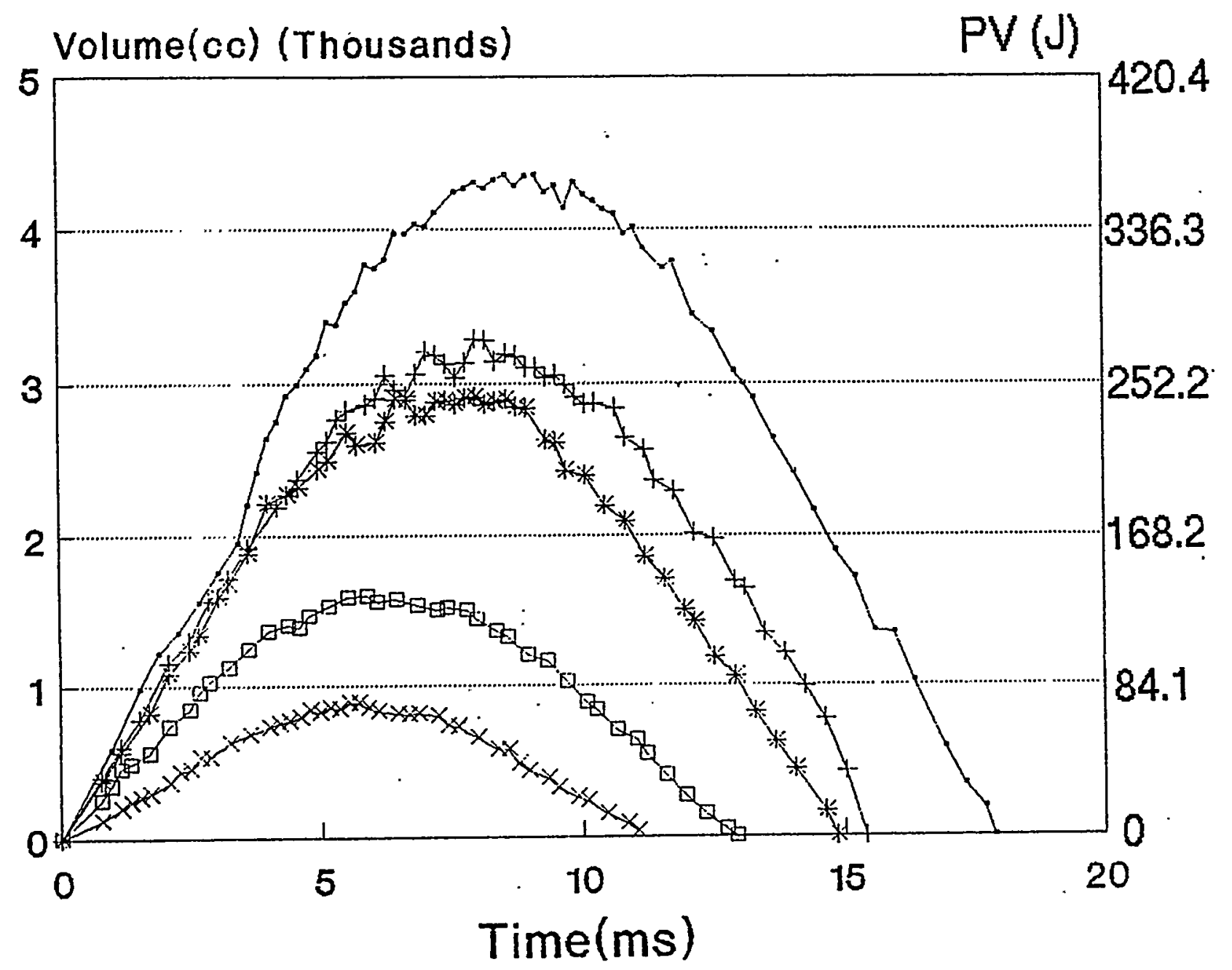

Figure 3. Bubble volumes vs. time for five capacitor discharges through underwater aluminum strips mounted between electrodes $1 \mathrm{~cm}$ apart. Weights of aluminum, energies and voltages that participate in the discharges may be found in Table 1 .

$$
\begin{aligned}
& \text { - 42-30-03 4 42-30-02 * 42-30-01 } \\
& \rightarrow 42-33-01 \quad \times 42-32-01
\end{aligned}
$$


In Figure 4, we plotted the maximum bubble volumes observed in Figures 2 and 3 as a function of the discharge energies. Notice both the linear form of the plots and the significant enhancement produced at each electrical energy when the fine tungsten filament was replaced with the equivalent aluminum strip. Linear regression analyses were performed on both sets of data and are included in Figure 4.

The pressure-volume product of the bubble may be compared to the electrical energy discharged through either the tungsten wire or the aluminum strip. We have converted the maximum bubble volumes, $V_{\max }$, to energies in joules by the equation

$$
E_{\text {joules }}=P V(J)=1013\left(P_{\mathrm{atm}}(\mathrm{MPa})\right)\left(\mathrm{V}_{\max }(\mathrm{L})\right)
$$

where $\mathrm{P}_{\mathrm{atm}}=0.085 \mathrm{MPa}$, the local atmospheric pressure. We have added scales of these PV maximum bubble energies at the right sides of the plots in Figures 2, 3, and 4 for comparison with the bubble volume scales at the left sides.

It should be mentioned that the equation above probably provides a conservative estimate of the bubble energy, because overexpansion may produce a momentary bubble pressure less than ambient. We have not attempted to correct for this effect, however.

It is interesting to compare the maximum bubble energies estimated from the PV product with the electrical energies discharged through the metallic conductors. As examples from Table 1, when $1000 \mathrm{~J}$ is discharged through the tungsten filament in experiment 42-34-3, the maximum PV bubble energy achieved is $70.4 \mathrm{~J}$. But when $1000 \mathrm{~J}$ is similarly discharged through a $17.3 \mathrm{mg}$ strip of aluminum in experiment 42-30-2, the corresponding bubble energy is $312 \mathrm{~J}$. Thus, about $7 \%$ of the electrical energy is converted to bubble energy when the discharge through the water plasma is initiated by vaporization of the tungsten filament. But when the same electrical energy is passed through a $17.3-\mathrm{mg}$ strip of aluminum, the "conversion" is increased to about $31 \%$ by the addition of the energy of the aluminum-water combustion reaction to the water plasma energy.

In Figure 5, we have attempted to separate the PV energy produced by the aluminum-water combustion from the PV energy generated by the electrical discharge through the water alone. To do this, we have subtracted the PV energies for the points on the lower plot in Figure 4 (the "tungsten bubbles") from those on the upper plot (the "aluminum bubbles"). We have then divided these differences in PV energies by the weight of the aluminum strip combusted to produce each aluminum bubble. We then plotted the resulting PV energies per mg of aluminum against the corresponding weight of the aluminum strip to produce the set of "conversion efficiencies" shown in Figure 5. We have also included two horizontal lines in Figure 5. The lower one shows the PV bubble energies that would be produced by the underwater explosions of a high explosive (for example, TNT) yielding about $4 \mathrm{~J} / \mathrm{mg}$ (Rightley et al. 1993) and the thermodynamic maximum of $17.1 \mathrm{~J} / \mathrm{mg}$ that might be expected from the aluminum-water reaction (Chase et al. 1988), shown as the upper line. Note that with masses of aluminum as small as $7 \mathrm{mg}$, we have achieved bubble energies about the same as those that would be expected from an equal weight of high explosive such as TNT. Additionally, by increasing the amount of aluminum to only $21.6 \mathrm{mg}$, we already seem to be approaching the thermodynamic maximum obtainable from the aluminum-water interaction. It should be noted that it is normally difficult 


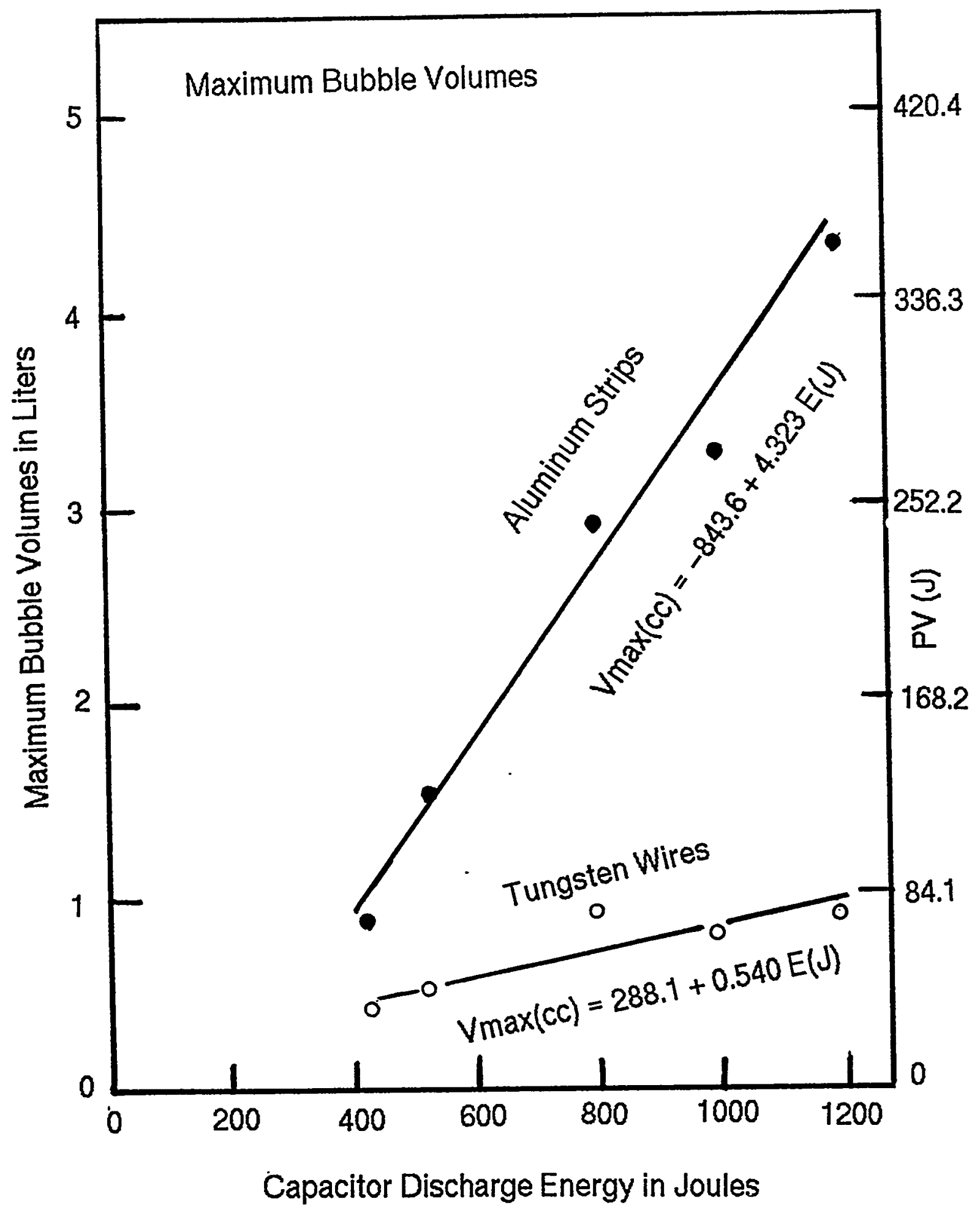

Figure 4. Maximum bubble volumes produced by capacitor discharges through underwater aluminum strips and tungsten wires plotted against capacitor discharge energies. Experimental details may be found in Table 1. 


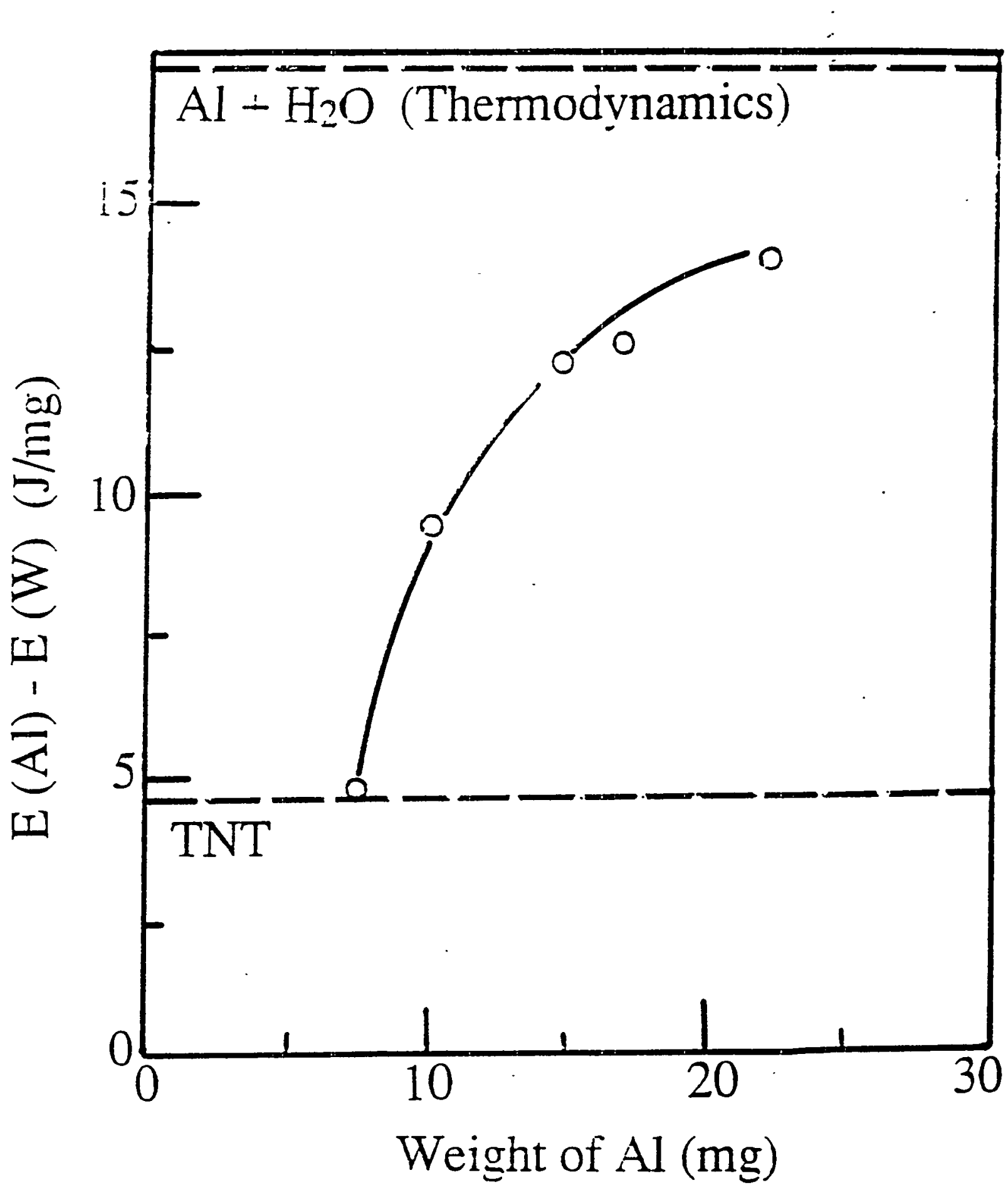

Figure 5. Bubble energies generated by aluminum-water interactions vs. weight of aluminum strips ignited by underwater capacitor discharges. Energies have been corrected for the corresponding baseline water plasma bubble energies determined from Figure 4. 
or impossible to initiate detonations of very small amounts of high explosives, for example, a few milligrams, as was done with the aluminum strips in this work.

\section{Current-Voltage Behavior}

When a capacitor is discharged between underwater electrodes, characteristic oscilloscope traces of the current and voltage indicate how the energy of the discharge is utilized during the explosion. Here we refer to the work of Lee and Ford 1988b for the techniques and interpretation of our current and voltage oscilloscope traces.

If conditions are favorable for spontaneous plasma formation in the water, or if there is a negligibly small conducting mass between the electrodes, then application of the voltage and the start of current flow will cause almost instantaneous breakdown. This will cause the resistance between the electrodes to become very high and thus lead to an immediate sharp rise in voltage, as shown in Figure 6. This is the situation that prevailed with the discharges through both the gold bridgewires (Nelson et al. 1994) and the fine tungsten wires used in this work, where the conductors vaporize very rapidly. With our circuit, the current flow that accompanies the vaporization of the tungsten wire and the discharge through the water reaches a maximum of approximately $14 \mathrm{kA}$ in about $30 \mu \mathrm{s}$. Because of the inductance of our circuit, this induces a voltage spike of approximately $20 \mathrm{kV}$, about $16 \mathrm{kV}$ higher than our charging voltage. See Lee and Ford 1988b for practical applications of inductive voltage enhancements such as these.

But when a metallic conductor with a substantial heat capacity is placed between the electrodes, there is a pause after the discharge begins. During this time, the current heats the metal. If the total energy discharged is sufficient, the metal may be heated through its melting and boiling temperatures. During this heat-up period, the resistance of the circuit remains essentially constant. This produces only a small voltage rise until the metal is removed from between the electrodes by fracturing, melting, vaporization or combustion, which then produces the high resistance. Thus, the high voltage spike is delayed significantly beyond the initiation of the discharge. This is shown in Figure 7 for a $21.6 \mathrm{mg}$ strip of aluminum foil $1 \mathrm{~cm}$-long between the electrodes. Here, the maximum current of $13.6 \mathrm{kA}$ is about the same as in Figure 6 , but now the peak voltage reaches only $11.5 \mathrm{kV}$, and is delayed by about $30 \mu \mathrm{s}$. Lee and Ford $1988 \mathrm{a}, \mathrm{b}$ have studied the effect of carefully adjusting the circuit parameters in order to maximize the efficiency of the metal-water combustion for a given electrical energy input. In the five vigorous $\mathrm{Al}+\mathrm{H}_{2} \mathrm{O}$ explosions presented in Table 1, however, we have intentionally overdriven our discharges to ensure total combustion of the aluminum. In practical applications in which pressure transients produced by metal combustion-enhanced discharge are to be synchronized with other high speed events, these delays caused by heatup of the metallic conductors must be accounted for. They are usually short, however, in relation to the main event, for example, triggering of a steam explosion, and can be disregarded. 


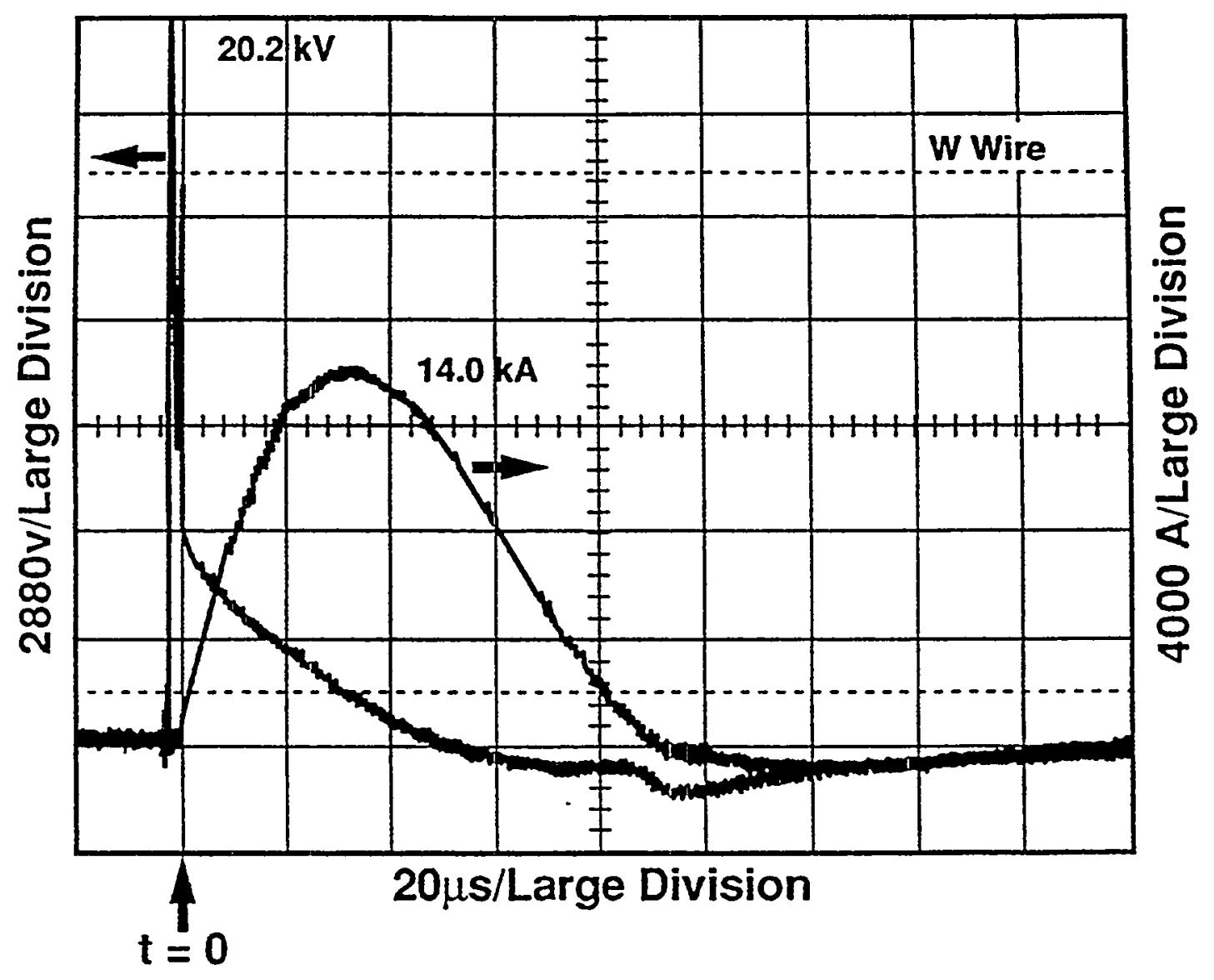

Figure 6. Current (lower with broad maximum) and voltage (with spike) traces produced when a $10 \mathrm{~mm}$ length of 0.0025 - $\mathrm{mm}$-diameter tungsten wire was exploded underwater with a $1200 \mathrm{~J}$ capacitor discharge at $4 \mathrm{kV}$ (42-34-2). 


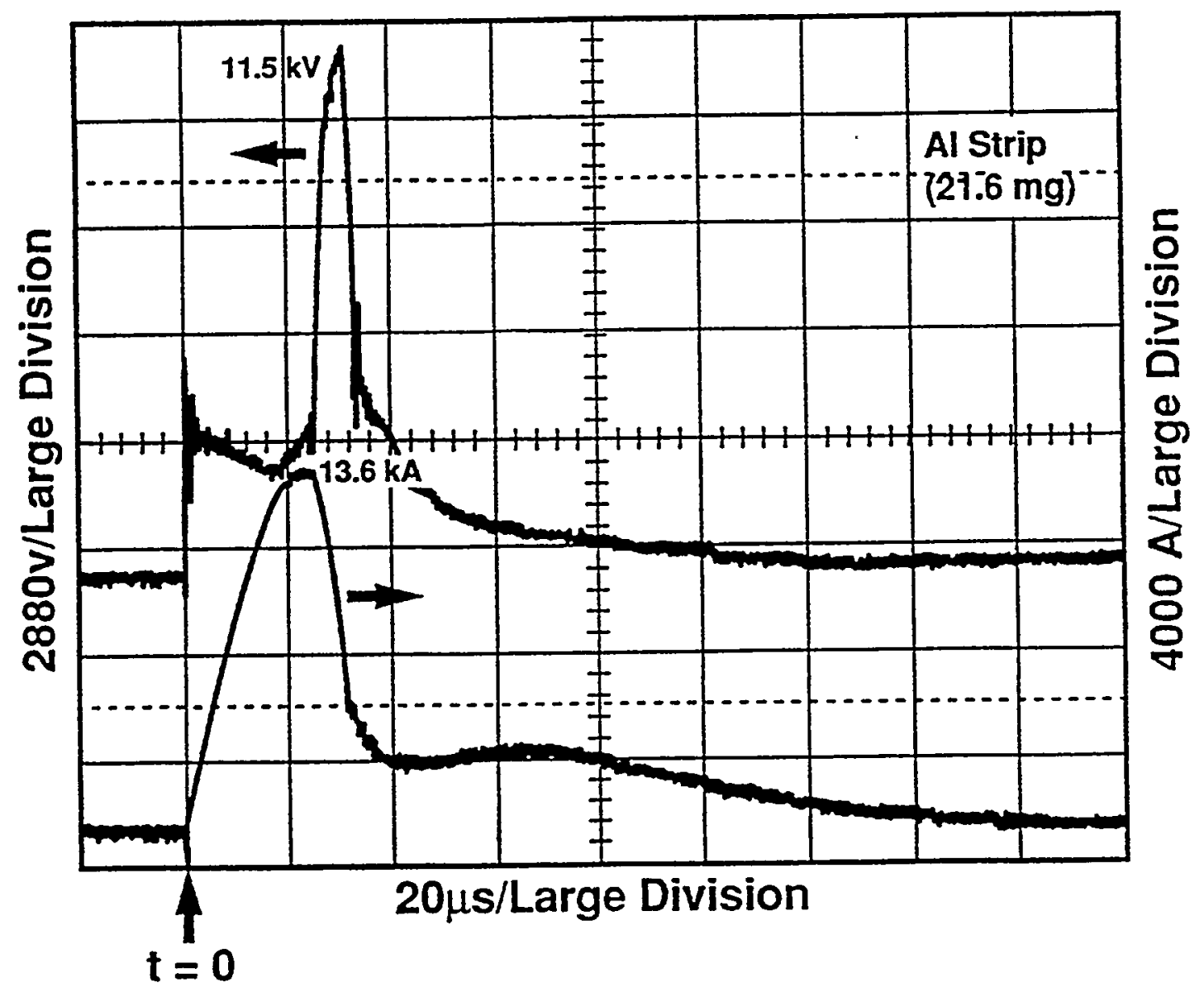

Figure 7. Current (lower) and voltage (upper, with spike) traces produced when a $32 \mathrm{~mm}$ length of $2 \mathrm{~mm} \times 0.13 \mathrm{~mm}$ strip of aluminum foil $(21.6 \mathrm{mg})$ was exploded underwater with a $1200 \mathrm{~J}, 4 \mathrm{kV}$ capacitor discharge (42-30-3). 


\section{Recording of Pressure Transients Underwater}

The use of transducers to faithfully and reliably record underwater pressure transients in a chamber as small as ours is complex, as discussed in Johnson et al. 1992. There are many external and internal artifacts that can confuse the signals recorded on oscilloscopes and similar devices. These include

- Electrical degradation of the signal produced by improper shielding, cable length, impedance, circuit response and the use of inadequate preamplification when needed. Another source of confusion may arise from the apparent production of shockwaves caused by spurious electrical noise. In our case, the electrical noise is caused by the discharge of a capacitor through the metallic conductors in close proximity to the transducers.

- Spurious signals generated by reflections of pressure transients from, or mechanical movements of, the supporting and neighboring structures used to position the transducer in the water. Often the transducer is mounted rigidly to the water chamber. The motion of the chamber produces signals that are not related to the discharge-generated shockwave and its responses in the water.

- The physical construction of the transducer may affect the signals obtained. For example, the active element of the transducer should be as thin as possible to permit the most faithful reproduction of the shockwave that passes through it. It is readily shown, for example, that the $0.76 \mathrm{~mm}$-thick tourmaline element used in Lee and Ford's experiments (1988b) may misinterpret a significant portion of the shockwave because of its tendency to integrate over shockwave travel time through the element. Our use of the PVDF transducer with a $100 \mu \mathrm{m}$-thick active element is inherently able to generate a more faithful signal.

- The duration of the signal that can be relied on (i.e., the write time) is also important. The PVDF transducer has a considerably shorter write time than the tourmaline transducer.

- Calibration of the transducers is not simple. The manufacturers supply calibrations of the commercial transducers, but frequently the values are not as reliable as desired for short time events and should be carefully examined before use.

We have used the concepts described in Johnson et al. (1992) to interpret our pressure transducer measurements. The work cited applied to chambers and shockwave generation situations similar to ours. In addition to the discussions in the work of Johnson et al. (1992), we have also directly compared the output of a commercial tourmaline transducer of the same type as used by Lee and Ford with the PVDF transducer. We placed them side by side at the same distance from the capacitor discharge, $103 \mathrm{~mm}$ (see Figure 1). A comparison of typical signals produced by the PVDF and tourmaline transducers is shown in Figure 8. It can be seen that the shape of the shockwave pulse and the magnitude produced by the thin PVDF element differs considerably from that obtained by the thicker tourmaline element shown in the lower trace. Moreover, the 


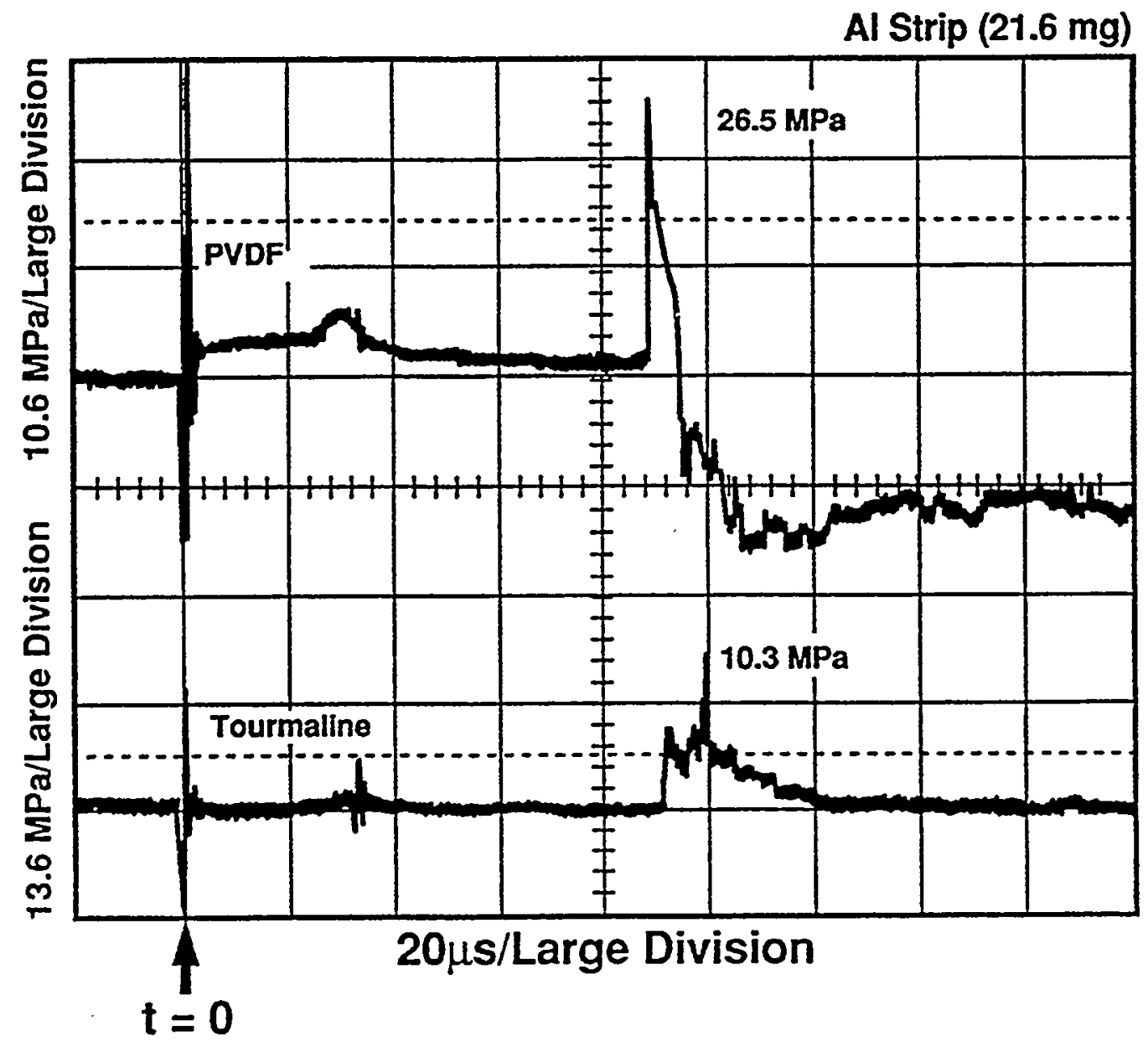

Figure 8. Pressure traces recorded at $103 \mathrm{~mm}$ with a PVDF (upper) and a tourmaline (lower) transducer produced by the underwater explosion of a $21.6 \mathrm{mg}$ strip of aluminum foil. Current and voltage traces for this experiment are shown in Figure 7. (42-30-3). 
peak pressure observed in the rising shockwave portion of the PVDF trace is almost three times greater than that obtained from the tourmaline transducer. We attribute this difference to the slower rise time of the tourmaline device. Thus, the peak pressures reported by Lee and Ford $1988 \mathrm{~b}$ of about $12 \mathrm{MPa}$ for the aluminum-water reaction may be considerably lower than the true peak pressures, possibly by as much as a factor of three. In our work we rely on the PVDF signals instead of the tourmaline transducer data; we realize, however, that while the PVDF transducer has a faster rise time, it still has inherent limitations for the faithful recording of the peaks in the pressure traces.

In Figure 8, we consider the pressure traces to be those deflections shown at about $90 \mu$ s after the electrical discharge is started at $t=0$. It should be noted that the travel time for the shockwave between the aluminum strip and the transducer is about $70 \mu$ s based on a travel velocity through the water of $1.5 \mathrm{~mm} / \mu \mathrm{s}$. The additional time is that required for the aluminum strip to ignite and emit the shockwave which requires about $30 \mu \mathrm{s}$ (see Figure 7). Although the small defections at 20 to $30 \mu \mathrm{s}$ in Figure 8 are probably related to the ignition of the aluminum, they are not completely understood at this time. Perhaps there is a generation of electrical noise associated with the combustion, or they may be related to the effect on both transducers of light emitted by the ignition and combustion.

\section{Aluminum Enhancement of Shockwaves}

In this section, we compare the peak shockwave pressures obtained with aluminum-enhanced underwater discharges with those produced by discharges at identical energies through fine tungsten wires. The metal combustion is important in the former situation, but it is always assumed negligible in the case of the tungsten wires.

We present a typical pair of pressure traces for the two metals recorded with the PVDF transducer in Figure 9. The upper trace was produced by the underwater discharge through a $21.6 \mathrm{mg}$ aluminum strip (this trace is also shown in Figure 8), while the lower trace was produced by the discharge of the identical capacitor energy through the fine tungsten wire. Note the substantial increase in peak pressure produced when the aluminum-water interaction is superimposed on the mostly simple arcing initiated by the tungsten wire. Notice again the delays between the arrival of the shockwave at the transducer after traveling the 103-mm distance through water from the source, plus the time required to raise the aluminum strip to the ignition temperature as shown in Figure 7. Both delays have been discussed in the previous section.

We should comment on two aspects of the traces shown in the figures: (a) the "negative pressures" measured by the PVDF gauge about $5 \mu$ s after the peak pressure shown on the traces in Figures 8 and 9, and (b) the "humps" in the PVDF gauge responses for discharges through both aluminum and tungsten at about 30 microseconds in Figure 9.

We believe (a) is an artifact caused by the unreliability of the PVDF transducer after the shockwave interacts with the backer block behind the gauge, as explained in Johnson et al. (1992). For these gauges, the active element was mounted on the face of a cylindrical brass backer $50 \mathrm{~mm}$ in diameter and $75 \mathrm{~mm}$ in length. The arrival time of radial release at the element 


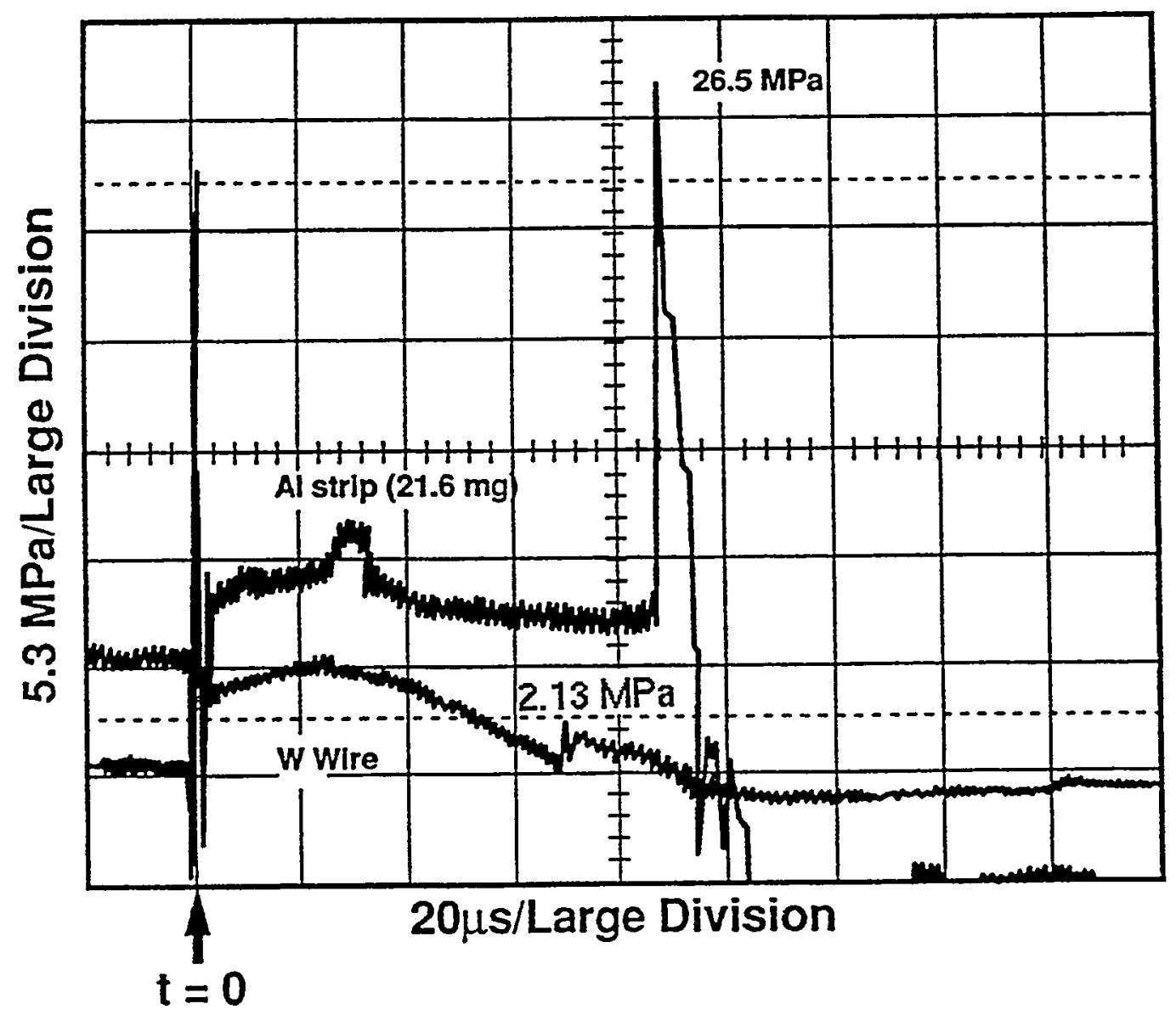

Figure 9. Comparison of pressure traces produced with a PVDF transducer at $103 \mathrm{~mm}$ by the underwater discharge of $1200 \mathrm{~J}$ at $4 \mathrm{kV}$ through a $21.6 \mathrm{mg}$ strip of aluminum (upper) and a $10 \mathrm{~mm}$ length of $0.025-\mathrm{mm}$ tungsten wire (lower). The difference between the shock arrival times at the transducer is caused by the approximately $30 \mu \mathrm{s}$ required to heat the aluminum to the ignition temperature as indicated by comparing Figures 6 and 7 . (42-30-3, 42-34-2). 
is calculated by dividing the radius, $25 \mathrm{~mm}$, by the sound speed in brass, $4.4 \mathrm{~mm} / \mu \mathrm{s}$. The result is $5.7 \mu \mathrm{s}$. Thus, the transducer signal is reliable for only about $6 \mu \mathrm{s}$ after the shockwave arrives at the PVDF element. This is very likely the explanation for the strong negative-going portion of the trace shown in Figures 8 and 9.

In regard to (b), the "hump" at $30 \mu \mathrm{s}$ in the upper curve is probably related to the burnout and ignition of the aluminum strip. This can be identified in the current and voltage curves shown in Figure 7, where burnout occurs at about $30 \mu \mathrm{s}$, causing the voltage to rise sharply and the current to fall. The "hump" may be caused by electrical effects and/or by the radiation generated as the aluminum ignites and burns. Note a similar deflection at this same time in the trace of the tourmaline transducer shown in Figure 8.

The "hump" in the lower curve in Figure 9 seems to indicate mostly a baseline drift of the transducer rather than a well-defined peak. It is probably not related specifically to the discharge through the tungsten wire.

We have measured the peak pressures generated by aluminum strips with five different weights, each initiated by the discharge of approximately 55 electrical $\mathrm{J} / \mathrm{mg}$ of metal. The peak pressures measured by the PVDF transducer $103 \mathrm{~mm}$ away are shown as the upper plot in Figure 10 as the function of the electrical discharge energy used to initiate the combustion. The lower curve in Figure 10 is a plot of the comparable peak pressures produced by discharging the same energy through the tungsten wires stretched between the $1 \mathrm{~cm}$-apart electrodes. Notice that when the aluminum combustion occurs, the peak pressures produced increase from about $5 \mathrm{MPa}$ to about $27 \mathrm{MPa}$ while the electrical discharge arcing through the water generated peak pressures that increase from 1.5 MPa to only about $2 \mathrm{MPa}$ over this same range of discharge energies ( $423 \mathrm{~J}$ to $1200 \mathrm{~J}$ ). (The lower curve with peak pressures of about $2 \mathrm{MPa}$ is consistent with the peak pressures measured at the same distance with the PVDF transducer when similar electrical energies were discharged through gold bridgewires as described by Nelson et al. 1994.) We have performed linear regression analyses of both the aluminum and tungsten data shown in Figure 10 and have included these results in that figure.

In Figure 11, we compare the enhancement of both the bubble growth and the peak pressures produced in the water by incorporating the combustion of the aluminum strips into the discharges. In the lower curve in this figure, we show the aluminum-to-tungsten enhancement ratios of the bubble volume data taken from Figure 4, while in the upper curve, we show the comparable relationships for the shockwave magnitudes taken from Figure 10. Note that over the range of aluminum weights and discharge energies studied here, the enhancement of the bubble volume for a given condition reaches about 5-fold, while the enhancement in the peak pressure, while not as reproducible, appears to reach 10- to 12-fold. We have also performed linear regression analyses of the enhancement ratios for both maximum bubble volumes and peak pressures. They are included in Figure 11. 


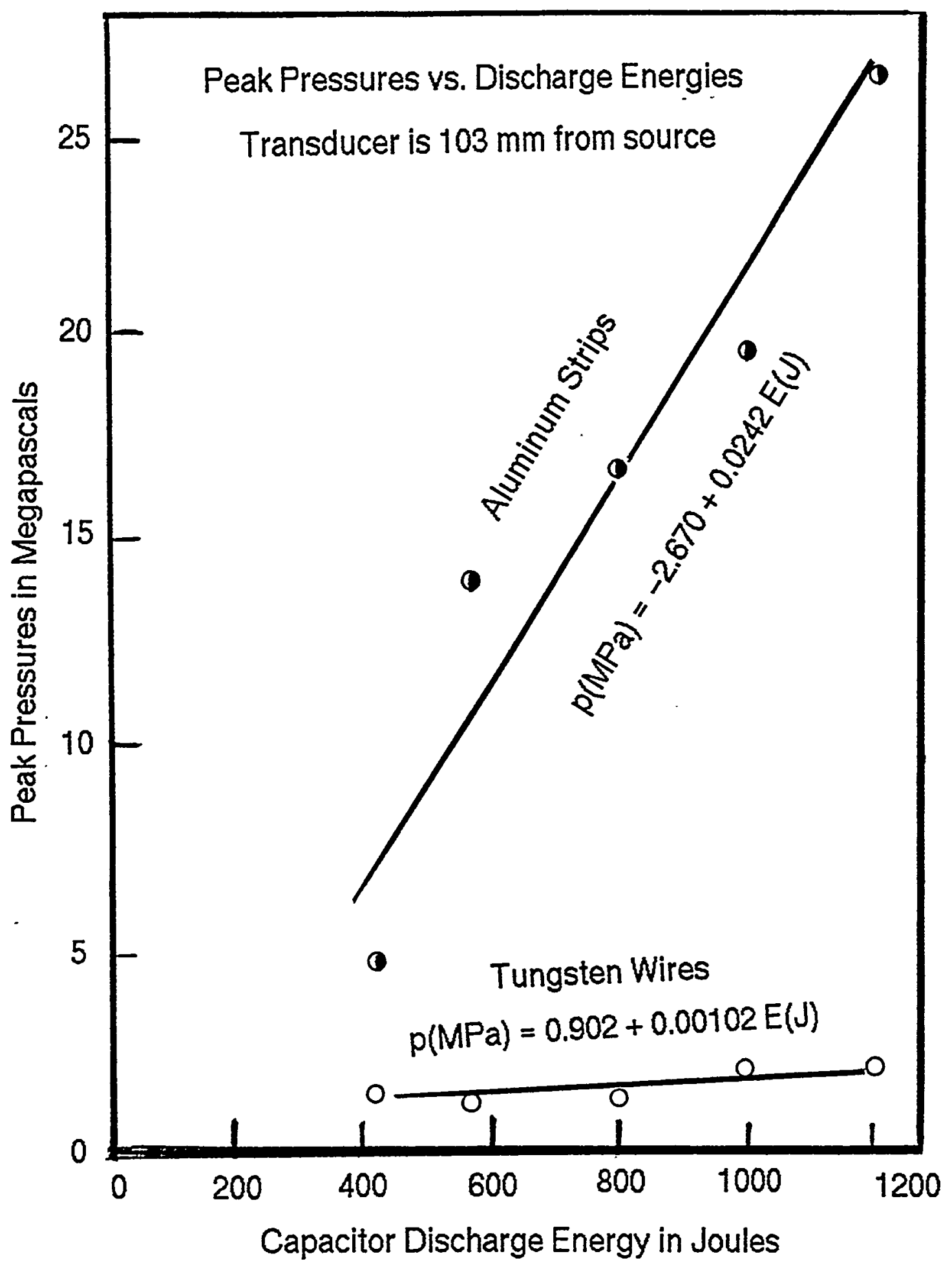

Figure 10. Peak pressures recorded at $103 \mathrm{~mm}$ with a PVDF transducer, produced when strips of aluminum foil or tungsten wires were exploded underwater with various discharge energies. Experimental details may be found in Table 1. 


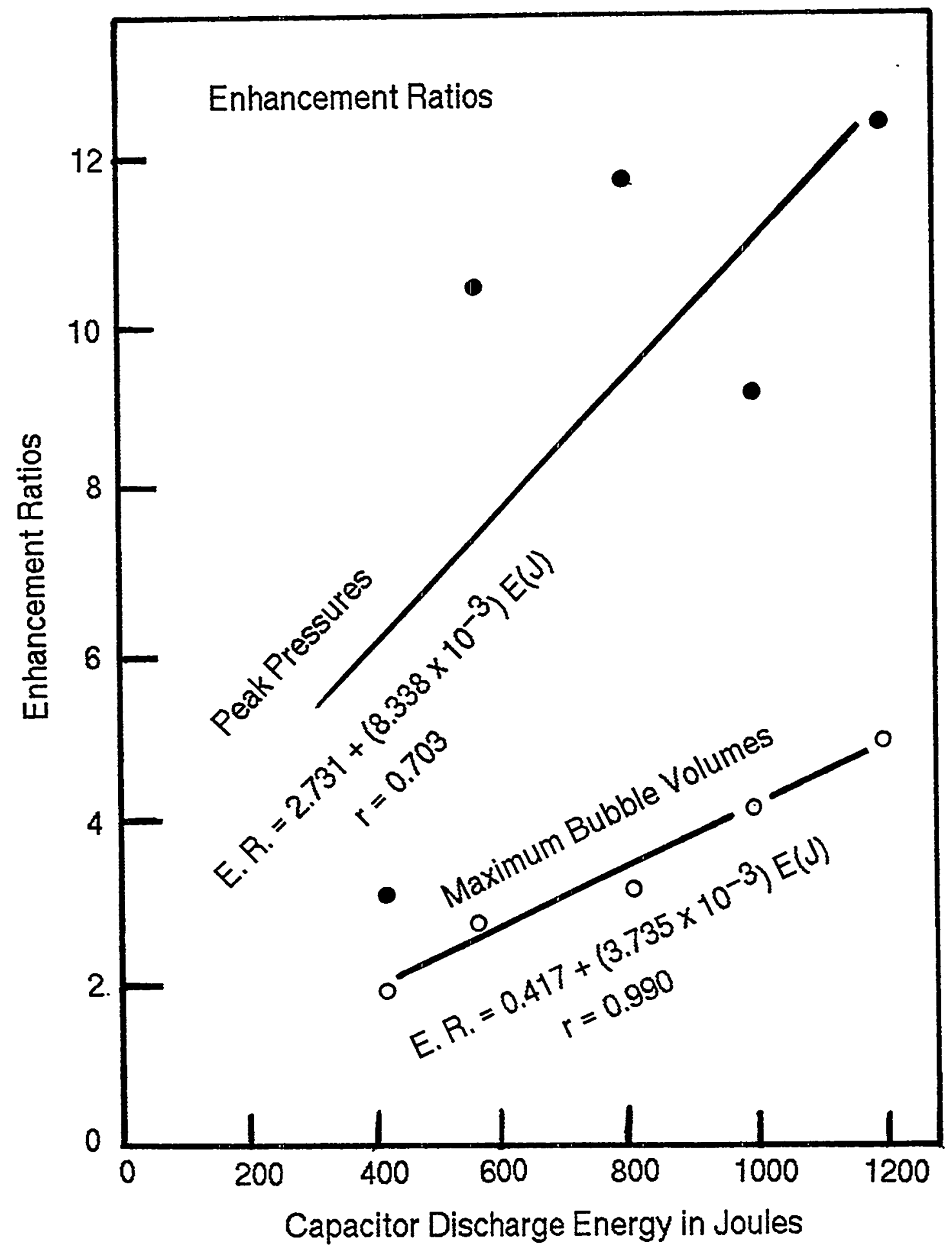

Table 11. Enhancements of peak pressures (upper plot) and maximum bubble volumes (lower plot) achieved by replacing fine tungsten wires with aluminum strips between electrodes and discharging the same electrical energies through them. Data are taken from Figures 11 and 4, respectively. Experimental details may be found in Table 1. 


\section{Discussion}

In order to test various hypotheses proposed to explain the triggering of steam explosions of single drops of molten materials, it is necessary to produce shockwaves and underwater bubble growths of magnitudes greater than those we have produced.in the past by discharging capacitors through gold bridgewires (Nelson et al. 1994). In the current work, we have demonstrated quantitatively that we can achieve at least order-of-magnitude increases in shockwave pressures and 5-fold increases in bubble volumes simply by changing from gold to aluminum conductors for our underwater discharges. We have accomplished this without increasing the electrical energies of the discharges used with the bridgewires (that is, without changing our power supply). This simple and inexpensive substitution of conductors generated energetic transients comparable to those produced with high explosives (HE) but with a number of advantages over the use of these hazardous substances in the laboratory setting.

\section{Comparisons with High Explosives}

Our work has shown that both the peak pressures and the underwater bubble growths produced by the aluminum enhancement procedure can easily overlap the ranges of these same quantities generated by the initiation of equivalent (small) weights of HE (see Figure 5). This is also indicated forcefully in Figure 12 in which we compare the maximum bubble volume of about 1 liter produced when a commercial RP-2 EBW detonator (manufactured by Reynolds Industries, San Ramon, CA) that contains $64 \mathrm{mg}$ of $\mathrm{HE}$ was exploded underwater (Beck 1991: Nelson et al. 1995) with the bubble volume-time behavior of the bubble produced by a $21.6 \mathrm{mg}$ strip of aluminum ignited underwater with a capacitor discharge (experiment 42-30-3; see Figure 3). In Figure 12, we have also included the bubble volume-time plot produced by the discharge of the same electrical energy through a fine tungsten wire (experiment 42-34-2; see Figure 2) to indicate the energetics of the bubble produced only by mostly electrical arcing in the water. The 5-fold enhancement of bubble volume shown in Figure 11 is also apparent in Figure 12. It is also apparent in Figure 12 that on a per gram of energetic material basis, the aluminum-enhanced discharge produces significantly greater bubble energy than the small RP-2EBW detonator (see Nelson et al. 1995 for further discussions of the bubble produced by this detonator).

We extend this comparison between the underwater explosion of small amounts of $\mathrm{HE}$ and aluminum-enhanced discharges in Table 2 . Here we present peak pressure and maximum bubble volume data for the $21.6 \mathrm{mg}$ aluminum strip (Figure 12) with similar data obtained mostly from Beck 1989 (cited in Table 2; also private communications) related to the underwater firing of both the Reynolds RP-2EBW detonator and another Reynolds detonator, the RP-1EBW that contains $604 \mathrm{mg}$ of HE. It can be seen in Table 2 that the peak pressures generated by the aluminum-enhanced discharge at the same distance are on the same order as those produced by the larger RP-1EBW detonator. However, the maximum bubble volume produced by the detonator with the larger mass of explosive is considerably larger than that produced by the aluminum-enhanced discharge. 


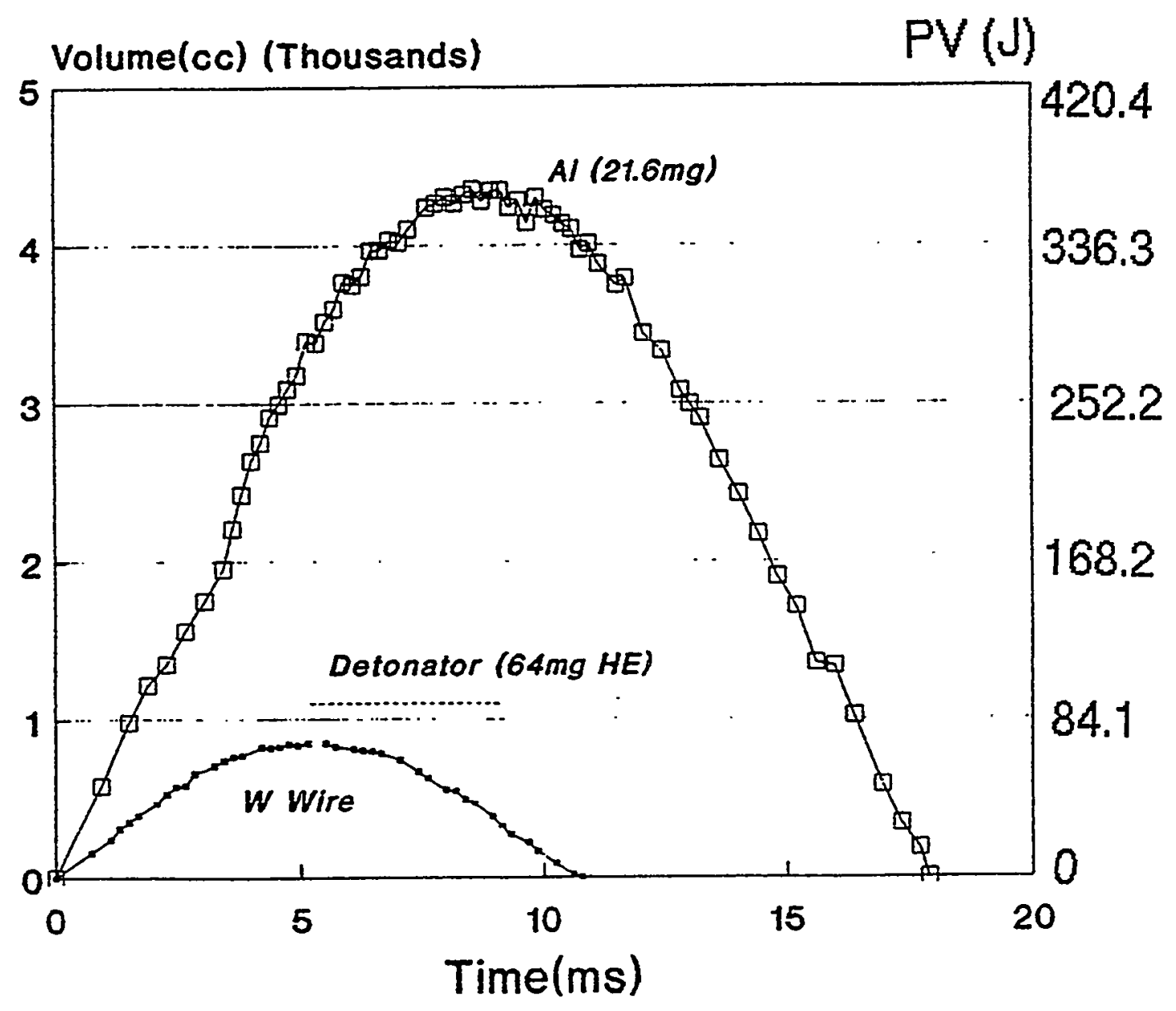

Figure 12. Comparison of the bubble volumes as a function of time produced by the underwater discharge of $1200 \mathrm{~J}$ at $4 \mathrm{kV}$ through a $21.6 \mathrm{mg}$ strip of aluminum foil (upper) and a $10 \mathrm{~mm}$ length of $0.0025-\mathrm{mm}$ tungsten wire (lower) (42-30-3, 42-34-2). See Table 1 for experimental details. Horizontal line indicates the maximum volume of a bubble produced by the underwater explosion of a commercial detonator that contains $64 \mathrm{mg}$ of high explosive. 
Table 2. Comparison of Underwater Aluminum-Enchanced Capacitor Discharge with Two Commercial Detonators Exploded Under Water

\begin{tabular}{|c|c|c|c|}
\hline $\begin{array}{l}\text { Explosive } \\
\text { Device }\end{array}$ & $\begin{array}{l}\text { Energetic } \\
\text { Mass (mg)' }\end{array}$ & $\begin{array}{c}\Delta \mathrm{p}_{\max } @ 100 \mathrm{~mm} \\
(\mathrm{MPa})\end{array}$ & $\begin{array}{l}\mathrm{V}_{\max } \\
\text { (liters) }\end{array}$ \\
\hline RP-1EBW Detonator & 604 & $\begin{array}{r} \\
28^{\mathrm{a}} \\
\sim 50^{\mathrm{b}}\end{array}$ & 31 \\
\hline RP-2EBW Detonator & 64 & $5.2^{\mathrm{a}}$ & 1.1 \\
\hline $\mathrm{Al}(42-30-3)$ & 21.6 & 26 & 4.8 \\
\hline
\end{tabular}

It is apparent then that the aluminum-water combustion initiated by the capacitor discharge has significant potential for producing underwater blast effects similar to those produced by small amounts of HE. Thus, the energetics for the aluminum enhanced discharge can easily exceed those of TNT at $4.6 \mathrm{~J} / \mathrm{mg}$ (Rightley et al. 1993); according to Figure 5 it seems that the bubble energies are approaching those of the thermodynamic maximum of the aluminum-water reaction of about $17.1 \mathrm{~J} / \mathrm{mg}$ (Chase et al. 1985). The comparison of aluminum and HE directly on a per gram basis may seem somewhat misleading. This is due in part to our failure to consider the external oxidizer needed to complete the interaction of a given mass of aluminum as part of the mass. However, even if the weight of water necessary to produce complete combustion of the aluminum (1 mg of water for $1 \mathrm{mg}$ of aluminum) is included, the energy produced per unit weight of total reactants is only halved to about $8.5 \mathrm{~J} / \mathrm{mg}$, still about twice the energy produced by the HE.

\section{Advantages of Aluminum Enhancement}

Although it might seem logical to follow Ciccarelli 1991 in his use of small amounts of HE (blasting caps) as more energetic triggering sources for steam explosions, there are many disadvantages to the use of $\mathrm{HE}$ in the laboratory. Thus, use of aluminum instead of $\mathrm{HE}$ as the energetic material is favored from a number of safety, environmental and health aspects. The aluminum may be transported, handled, and stored safely without protective enclosures, special training, and certification of personnel and also avoids various possible local restrictions. The 
cost of the aluminum is minimal, provided the capacitors and power supply are available. Moreover, its chemical reaction products $-\mathrm{H}_{2}$ and $\mathrm{Al}_{2} \mathrm{O}_{3}$-are nontoxic and environmentally benign. Although the amount of permanent gas generated per $\mathrm{mg}$ of aluminum $(1.24 \mathrm{cc}$ of hydrogen at STP) is somewhat greater than the amount of permanent gas produced by HE (about $0.5 \mathrm{cc} / \mathrm{mg}$ ), the $\mathrm{H}_{2}$ gas generated from the aluminum-water reaction is nontoxic compared to those gases possibly produced by the high explosives (e.g., carbon monoxide and the oxides of nitrogen plus organic pyrolysis gases). Moreover, the aluminum does not produce the undesirable debris fragments (e.g., detonator parts, unburned materials) that usually accompany the detonation of even small amounts of $\mathrm{HE}$.

Another advantage of the aluminum-enhanced discharge is that it can be used to produce much smaller detonations than can normally be achieved with.HE because of the minimum mass required to detonate $\mathrm{HE}$. Thus, we were able to study fully developed shockwave-generating detonations with as little as $7 \mathrm{mg}$ of aluminum (see Figure 10), whereas the Type RP-2EBW detonator with $64 \mathrm{mg}$ of aluminum seems to be generating shockwaves very inefficiently when compared with the larger Type RP-1EBW detonator with $604 \mathrm{mg}$ of high explosive (see Table 2).

There is also significant potential for increasing the aluminum enhancement by various alloying procedures, as indicated by Lee and Ford 1988a. They observed that the metal ignition required less energy and occurred more rapidly when the aluminum was alloyed with 2 w/o lithium than the pure aluminum. This advantage, unfortunately, may be offset somewhat by the difficulty of obtaining the proper alloy in wire or thin strip form.

\section{Triggering of Steam Explosions with Shockwaves}

Beck et al. 1991 have pointed out the need for a coherent experimental program to investigate trigger effects on single drop steam explosions. They suggest that the effects of pressure transients with wide ranges of peak pressures and impulses on the initiation of the explosions should be studied.

Following their suggestions, several single drop steam explosion experiments have been performed recently to investigate the effects of applying shockwave triggers with peak pressures increased by about an order of magnitude. Nelson et al. attempted to trigger drops of melt in free fall through water with horizontally directed shockwaves generated by bridgewires discharged at the inner focus of a submerged semiellipsoidal reflector; the drop was at the outer focus when the bridgewire was fired. This has been attempted with drops of molten aluminum (Nelson 1995) and also with drops of thermite-generated iron-alumina melts of two compositions (Nelson et al. 1992). Contrary to expectations, the drops of the three melts triggered very poorly with the focused shockwaves compared to those with order-of-magnitude lower peak pressures generated by the same electrical energy discharged through gold bridgewires at the same distance but without the reflector. Moreover, Ciccarelli 1991 has studied the effects on drops of molten tin of increasing shockwave peak triggering pressure over the approximate range of 1 to $20 \mathrm{MPa}$. These shockwaves were applied to the drops from below; they were generated by capacitor discharges through thin copper wires placed inside the lower end of a vertical, water-filled steel pipe that pointed upward toward the falling drop of melt. For the molten tin drops Ciccarelli 
found that once a threshold peak pressure of about $2 \mathrm{MPa}$ had been exceeded, the steam explosions were essentially unchanged over the range 2 to $20 \mathrm{MPa}$.

On the basis of the work by both Nelson et al. and Ciccarelli 1991, it is shown that increasing the peak triggering pressures does not necessarily produce stronger steam explosions, at least for drops of the four melts studied: aluminum, tin and iron-alumina drops of two compositions released at temperatures that span a range greater than $1000 \mathrm{~K}$.

It is important to point out, however, that the pressure-time profiles of the shockwave triggers applied to these four melts were not strictly comparable. The shockwaves applied to the tin drops by Ciccarelli were produced over the entire range of pressures by a wire explosion at the bottom of a water-filled steel pipe. The low peak pressure shockwaves used by Nelson et al. were produced by exploding unconfined bridgewires in the water, while those of high peak pressure were produced by partially enclosing the bridewires in a semiellipsoidal reflector. Thus, the tin drops were exposed to an upward-traveling essentially planar initial shock front followed by many lesser shock fronts. These shock fronts were caused by reflections from the sidewalls of the pipe (see Nelson et al. 1994, for pressure profiles produced by bridgewires exploded in a water-filled steel pipe). On the other hand, the aluminum and thermite drops at low trigger pressures were exposed to sideways directed, outward radiating spherical shockwaves produced by the unconfined bridgewire discharge. At high trigger pressures, when the bridgewires were discharged in a reflector, the drops were subjected to sideways-directed conical shockwaves focused approximately to a sharp point at the one side of the drop. The pressure-time profiles of both the low- and high-magnitude triggers applied to both aluminum and thermite drops were essentially single short pulses with negligible pulse activity afterward (see Nelson et al. 1994).

The primary goal of the studies reported here has been to outline procedures to generate reproducible single triggering shockwave pulses with an order-of-magnitude range of peak pressures for use in steam explosion experiments, primarily with single drops of melt. These procedures should provide a smoothly variable set of pressure transients to test the recent suggestions of Beck et al. 1991 and Ciccarelli 1991 that pertain to the mechanisms of triggering single drops of melts in potentially explosive film boiling situations.

We feel that the aluminum-enhancement of underwater electrical discharges readily provides the desired 10-fold increase in peak triggering pressures without the need for reflectors or a new and larger capacitor bank. The use of an unconfined essentially point-source underwater exploding conductor produces a straightforward set of essentially spherically expanding shockwaves over the entire range of triggering peak pressures that are readily measurable with thin, short writetime PVDF transducers (Johnson et al. 1993). Moreover, the effects of water flow on triggering (Ciccarelli 1991) and the discharge energetics may be studied by the bubble growths produced by the explosions unencumbered by the cylindrical or semiellipsoidal enclosures used by Ciccarelli 1991, Nelson et al. 1992, and Nelson 1995. Finally, because aluminum-enhanced discharges comfortably widen the ranges of both peak pressures and bubble growth produced by electrical discharges across those produced by the detonation of small amounts of $\mathrm{HE}$, they can provide information for unifying many studies of both triggering and propagation of steam explosions performed in the past. 


\section{Conclusions}

To meet the increasing need for generating stronger pressure transients and bubble growths in water without using very large power sources or high explosives, we have investigated the underwater electrical explosions of aluminum strips that react chemically with the surrounding water. We found that identical capacitor discharges passed through aluminum conductors could produce as much as a 12-fold increase in the peak pressures and about a 5-fold increase in maximum bubble volumes above those produced by nonchemical electrical breakdown between the same submerged electrodes. Thus, we were able to increase the maximum capability of our capacitor bank to produce these transients in water by an order of magnitude for use in a variety of steam explosion triggering applications.

To produce these energetic aluminum explosions, it is necessary to discharge sufficient energy to raise the aluminum strip to an ignition temperature well above the melting point. We found a threshold of about $24 \mathrm{~J} / \mathrm{mg}$ of aluminum below which the metal simply parted by partial melting. But as the discharge energy was increased above this threshold, energetic metal-water chemical reactions began to set in that were accompanied increasingly by the emission of light. To ensure complete combustion of the metal in our experiments, we discharged about $55 \mathrm{~J} / \mathrm{mg}$ through each strip.

The maximum bubble volumes produced by our exploding aluminum strips achieved PV energies as high as about $14 \mathrm{~J} / \mathrm{mg}$ of aluminum for our most energetic bubble. These energies are approaching the thermodynamic limit of about $17 \mathrm{~J} / \mathrm{mg}$ for the aluminum-water reaction and are considerably larger than the corresponding PV energies of about $4 \mathrm{~J} / \mathrm{mg}$ achieved by the underwater detonation of high explosives. Moreover, it is also possible to achieve detonations with amounts of aluminum as small as about $7 \mathrm{mg}$, far below the minimum masses of high explosives with which detonations can be achieved.

Compared to the use of high explosives in the laboratory, the use of aluminum-water explosions offers many advantages such as low cost, easy availability, safety in transit and storage, and the avoidance of the many administrative, construction, personnel and good neighbor requirements mandated by the use of high explosives. 
, 


\section{References}

Anderson, R.P., and Armstrong, D.R., 1981, "Experimental Study of Small-Scale Explosions in an Aluminum-Water System," presented at the Winter Annual Meeting of the American Society of Mechanical Engineering, Washington, DC, November 15-20, and published in Fuel-Coolant Interactions, ASME HTD 19, 31-40.

Arakeri, V.H., Catton, I., Kastenberg, W.E., 1978, "An Experimental Study of the Molten Glass/Water Thermal Interaction Under Free and Forced Conditions,".Nucl. Sci. Eng. 66, 153-66.

Beck, D.F., 1989, Memorandum, D.F. Beck to M. Berman, Underwater Detonator Performance in Triggering Studies, Sandia National Laboratories, Albuquerque, NM.

Beck, D.F., Berman, M., and Nelson, L.S., 1991, "Steam Explosion Studies with Molten IronAlumnia Generated by Thermite Reactions," Dynamics of Detonations and Explosions:

Explosion Phenomena, edited by A.L. Kuhl, J.-C. Leyer, A.A. Borisov, and W.A. Sirignano, Vol. 134 of Progress in Astronautics and Aeronautics, AIAA, Washington, DC, pp. 326-355.

Buxton, L.D., and Nelson, L.S., 1975, Core Meltdown Experimental Review, SAND74-0382, Chapter 6, Sandia National Laboratories, Albuquerque, NM.

Chase, M.W., Jr., Davies, C.A., Downey, J.R. ,Jr., Frurip, D.J., McDonald, R.A., and Syverud, A.N., 1985, "JANAF Thermomechanical Tables, Third Edition," J. Phys. Chem. Reference Data, Volume 14, Supplement No. 1.

Chaussy, Ch., Schmiedt, E., Jocham, D., Fuchs, G., Brendel, W., Forssmann, B., and Hepp, W., 1986, Extracorporeal Shock Wave Lithotripsy, Technical Concept, Experimental Research, and Clinical Application, 2nd Ed., Karger, Basel.

Ciccarelli, G., 1991, "Investigation of Vapor Explosions with Single Molten Metal Drops in. Water Using Flash X-ray," Thesis, Department of Mechanical Engineering, McGill University, Montreal, Quebec, Canada. Also see Ciccarelli, G. and Frost, D.L., 1994, "Fragmentation Mechanisms Based on Single Drop Steam Explosion Experiments Using Flash X-ray Radiography," Nucl. Eng. Des. 146, 109-132.

Corradini, M.L., Kim, B.J., and Oh, M.D., 1988, "Vapor Explosions in Light Water Reactors: A Review of Theory and Modelling," in Progress in Nuclear Energy, 22, 1-117.

Cronenberg, A.W., and Benz, R., 1980, "Vapor Explosion Phenomena With Respect to Nuclear Reactor Safety Assessment," in Advances in Nuclear Science and Technology, J. Lewins and M. Becker, eds., Plenum Press, New York, NY.

Dullforce, T.A., Buchanan, D.J. and Peckover, R.S., 1976, "Self-Triggering of Small-Scale FuelCoolant Interactions: I. Experiments," Journal of Physics D: Applied Physics, 9, 1295-1303. 
Epstein, S.G., and Miller, R.E., 1987, "Causes and Prevention of Molten Aluminum-Water Explosions," Light Metals 1987, The Metallurgical Society of AIME, Warrendale, PA, pp. 693698.

Flory, K., Paoli, R., and Mesler R., 1969, "Molten Metal-Water Explosions," Chemical Engineering Progress, 65, 50-54.

Hyndman, D.A., and Gaffney, E.S., 1989, Development of PVDF Water Shock Gauges, KTECH TR-89-19, Ktech Corporation, Albuquerque, NM.

Johnson, D.E., Hogeland, S.R., and Nelson, L.S., 1992, "PVDF Water-Shock Pressure Transducer With 200 ns Response," Paper prepared for presentation at the 63rd Shock and Vibration Symposium, October 27-29, 1992, Las Cruces, NM.

Kim, B., and Corradini, M.L., 1984, "Recent Film Boiling Calculations: Implication on FuelCoolant Interactions," Fifth Int. Meeting on Thermal Nuclear Reactor Safety, Karlsruhe, W. Germany, Vol. 2, pp. 1098-1107.

Kondo, S., Togo Y., and Iwamura T., 1976, "A Simulation Experiment and Analysis on the Effects of Incoherence in Fuel Coolant Interaction," PNC N251, 76-12, 285-305.

Lee, W.M., 1991, "Metal/Water Chemical Reaction Coupled to a Pulsed Electrical Discharge," Journal of Applied Physics, 69, 6945-6951.

Lee, W.M., and Ford, R.D., 1988a, "Reactivity of Al-2.5\% Li with Water as Studied by the Exploding Wire Technique," Met. Trans., B19, 255-259.

Lee, W.M., and Ford, R.D., 1988b, "Pressure Measurements Correlated with Electrical Explosion of Metals in Water," J. Appl. Phys., 64, 3851-3854.

Nelson, L.S., and Duda, P.M., 1981, Steam Explosion Experiments with Single Drops of Iron Oxide Melted with a $\mathrm{CO}_{2}$ Laser, Sandia National Laboratories, Albuquerque, NM, NUREG/CR2295, SAND81-1346.

Nelson, L.S., and Duda, P.M., 1982, "Steam Explosion Experiments with Single Drops of Iron Oxide Melted with a $\mathrm{CO}_{2}$ Laser," High Temperatures, High Pressures, 14, 259-281.

Nelson, L.S., and Duda, P.M., 1983, "Steam Explosions of a Metallic Melt as its Degree of Exidation Increases: $\mathrm{Fe}, \mathrm{FeO}_{1.0}$, and $\mathrm{FeO}_{1.2}$ " Proc. Int'l Mtg. on Thermal Nuclear Reactor Safety, Aug. 29 - Sept. 2, 1982, Chicago, IL, U.S. Nuclear Regulatory Commission, Washington, DC, NUREG/CP0027, Vol. 2, 981-986.

Nelson, L.S., and Duda, P.M., 1985, Steam Explosion Experiments with Single Drops of Iron Oxide Melted with a $\mathrm{CO}_{2}$ Laser, Part II, Parametric Studies, Sandia National Laboratories, Albuquerque, NM, NUREG/CR-2718, SAND82-1105. 
Nelson, L.S., Duda, P.M., Hyndman, D.A., Allison, D.K., and Hyder, M.L., 1995, Thermal and Ignition-Type Steam Explosions of Single Drops of Molten Aluminum, Westinghouse Savannah River Company, Aiken, SC, WSRC-RP-95-718.

Nelson, L.S., Fuketa, T., Eatough, M.J., Vigil, F.J., Szklarz, D.D., Wong, C.C., and Hyndman, D.A., 1992, Steam Explosions of Single Drops of Thermite-Generated Melts: 25 and 50 Weight Percent Aluminum-Iron Oxide Initial Mixtures, SAND90-0511, Sandia National Laboratories, Albuquerque, NM.

Nelson, L.S., Hogeland, S.R., and Utash, J.L., 1994, Bubble Growth, Shock Waves and Flow Transients Produced by Underwater Capacitor Discharges, SAND93-0765, Sandia National Laboratories, Albuquerque, NM.

Nelson, L.S., 1995, "Steam Explosions of Single Drops of Pure and Alloyed Molten Aluminum," Nucl. Eng. Des., 155, 413-425.

Peppler, W., and Till, W., 1986, "Mechanisms Observed During Triggered Fragmentation of a Droplet of Molten Alumina in Water," Proc. Int. Conf. Sci. Technol. Fast Reactor Safety., 2, 497-502.

Reid, R.C., 1983, "Rapid Phase Transitions from Liquid to Vapor," Advances in Chemical Engineering, 12, 105-208.

Rightley, M.J., Beck, D.F., and Berman, M., 1993; NPR/FCI EXO-FITS Experiment Series Report, SAND91-1544, Sandia National Laboratories, Albuquerque, NM.

Sharon, A., and Bankoff, S.G., 1981, "Fuel-Coolant Interactions in a Shock Tube with InitiallyEstablished Film Boiling," PCH, PhyusicoChem. Hydrodyn., 2,177-202.

Shoji, J., and Takagi, N., 1983, "An Experimental Study of Small-Scale Vapor Explosions for Molten Tin Dropped Into Water," Bulletin of the Journal of the Society of Mechanical Engineers, 26 (215), 791-796. 


\section{Appendix A}

\section{Correlation Between Maximum Bubble Volumes And Bubble Growth Rates}

For a number of years, we have photographed the growth of bubbles in water with a Hycam high speed $16 \mathrm{~mm}$ framing camera. The bubbles were generated with various rapid underwater energy releases produced by

a. Capacitor discharges through underwater gold and tungsten bridgewires (Nelson et al. 1994, this work);

b. Chemically enhanced capacitor discharges through underwater graphite conductors ("penciled" bridgewires) and aluminum strips (this work);

c. Thermal-type steam explosions of drops of various molten materials, e.g., molten iron oxides (Nelson and Duda 1981, 1982, 1983, 1985), thermitegenerated iron-alumina melts (Nelson et al. 1992) and molten aluminum (Nelson 1995; Nelson et al. 1995);

d. One ignition-type steam explosion of a drop of molten aluminum (Nelson 1995, Nelson et al. 1995); and by the

e. Underwater detonation of small amounts of high explosives (Beck 1989; also Beck as cited by Nelson 1995 and Nelson et al. 1995).

An important parameter to be determined in these studies was the maximum volume achieved by the bubble, which then could be related to the PV energy released into the water by the initiation event.

On a number of occasions, we were unable to measure the maximum bubble volume on a given film record because of interference by one or more artifacts during the operation of the camera. These artifacts would result in the inability to use parts of the film at the time of maximum bubble growth. Some of these artifacts are related to bubble growth behavior; several examples follow.

a. Obscuration of the bubble by a structure, e.g., a window housing or a support.

b. Distortion of the bubble as it strikes a solid or other underwater discontinuity.

c. Early interruption of the bubble growth because it breaks through the surface of the water.

d. Early interruption of the bubble growth because of failure of the water chamber. 
e. Obscuration of the bubble growth by the generation of opacity in the water, e.g., by the formation of an array of tiny cavitation bubbles or a cloud of precipitate.

f. The formation of several bubbles in an interaction which overlap and ultimately coalesce into one or more larger bubbles.

Other artifacts arise from photographic difficulties, such as

g. Malfunction of the camera or photographic lights during bubble growth.

h. Insufficient length of film in the camera.

i. Improper start time and/or run time settings for the camera.

j. Damage to a portion of the film during loading or unloading, operation of the camera, handling or processing of the film, or during projection of the film.

k. Improper exposure settings, especially settings used to compensate for the speedup of the camera during operation.

1. Superimposition of luminosity that overexposes the film at some stage of the imaging.

Although these artifacts are cited for the imaging with high-speed photography, many (and perhaps others) could also apply to other recording techniques, such as video and image converter imaging.

There is one particularly unfortunate example of the difficulties that can be encountered with artifacts of this sort. In the only ignition-type steam explosion of any molten material observed in our laboratory (Experiment No. 30-80-1 reported in Nelson et al. 1995; see also Nelson 1995), we lost important information when the bubble had grown to about $15 \mathrm{~L}$ (we had normally been photographing bubbles with maximum volumes of about $1 \mathrm{~L}$ ). This bubble was generated by the triggered interaction between liquid water at nominally $298 \mathrm{~K}$ and a $10 \mathrm{~g}$ globule of molten pure aluminum at $1500^{\circ} \mathrm{C}$. After the bubble had grown to about $15 \mathrm{~L}$ in about $5 \mathrm{~ms}$, artifacts $\mathrm{c}$ and $\mathrm{d}$ abruptly terminated any further useful information about the volume of this one-of-a-kind bubble.

During analyses of our high-speed films recorded in this and earlier work with underwater capacitor discharges and steam explosions, we have noted that the bubble volume-time plots seem to resemble inverted Vs. These plots show essentially constant growth and collapse portions connected with a somewhat rounded top. The maximum bubble volume is usually only slightly less than the extrapolated peak of the inverted Vs in the plots. For examples, typical volume-time plots with this shape are shown in Figures 2, 3, and 12 in this report. We have hypothesized, then, that if the maximum bubble volumes, $V_{\max }$, are plotted against the bubble growth rates, $\mathrm{dV} / \mathrm{dt}$, we ought to obtain a linear correlation useful for estimating maximum bubble volumes that, for some reason, cannot be measured directly on our films. The negative 
slopes of dV/dt for collapsing bubbles will probably also correlate similarly with $\mathrm{V}_{\max }$ 's, we have not examined this, however.

Nelson et al. 1995 and Nelson 1995 resorted to an approximate method based on this hypothesis to estimate $V_{\max }$, the maximum volume achieved by the bubble in the ignition-type steam explosion. This was done by comparing the slope $\mathrm{dV} / \mathrm{dt}$ of the steam explosion bubble as it grew to $15 \mathrm{~L}$ with the (fortuitously) nearly identical slope observed during the growth of a different bubble generated underwater by the detonation of a high explosive detonator (Beck 1989, private communication). It was possible to assume that the maximum volume achieved by the steam explosion bubble that was lost at $15 \mathrm{~L}$ would have been approximately equal to the $30 \mathrm{~L}$ maximum volume achieved by the high explosive bubble. The high explosive bubble grew in a chamber that did not fail, the bubble did not burst through the surface of the water, and could be measured from properly exposed photographic images. (Nelson et al. 1995 and Nelson 1995 assumed, without proof, that bubbles produced by high explosives and by the underwater combustion of molten aluminum both grew and otherwise behaved identically.)

In order to estimate the maximum volumes of only partially measurable bubbles when an identical bubble is unavailable, we previously investigated linear interpolations and perhaps short extrapolations of correlations between $\mathrm{V}_{\max }$ and $\mathrm{dV} / \mathrm{dt}$ for bubbles that grew to about $\mathrm{V}_{\max }=0.8$ $\mathrm{L}$ (Nelson et al. 1994). These bubbles were generated by discharging capacitors at various energies through submerged gold bridgewires and a few "penciled" bridgewires. The correlation produced by linear regression analysis of these $\mathrm{V}_{\max }-\mathrm{dV} / \mathrm{dt}$ data showed

$$
\mathrm{V}_{\max }\left(\mathrm{cm}^{3}\right)=-67.93+3.14 \mathrm{dV} / \mathrm{dt}(\text { liters } / \mathrm{s})
$$

with a correlation coefficient of 0.96 . The linearity of the correlation thus seems reasonably valid at least up to $\mathrm{V}_{\max }$ of about $0.8 \mathrm{~L}$.

In order to test correlations of this sort properly, it would seem important, then, to generate a maximum bubble volume-growth rate plot over as wide a range of volumes as possible. In our new work, we achieved considerably larger maximum bubble volumes, as large as about $4.5 \mathrm{~L}$, with similar capacitor energies discharged through underwater aluminum strips as shown in Figures 3 and 4. Again, as in the work with gold and "penciled" bridgewires (Nelson et al. 1994), we obtained a linear relationship between the aluminum-enhanced maximum bubble volumes, $\mathrm{V}_{\max }$, and their slopes, $\mathrm{dV} / \mathrm{dt}$, as the amounts of aluminum ignited by the discharge increased from $7.6 \mathrm{mg}$ to $21.6 \mathrm{mg}$; here the maximum bubble volumes increased from about 1 to 4.5 L. These data are plotted in Figure A-1. A linear regression analysis performed on the aluminum-enhanced bubbles produces the equation

$$
\mathrm{V}_{\max }\left(\mathrm{cm}^{3}\right)=-841.8+8.02 \mathrm{dV} / \mathrm{dt} \text { (liters/s) }
$$

with a correlation coefficient of 0.993.

We have superimposed the linear regression analysis for the earlier, smaller, mostly gold bridgewire-generated bubbles given by equation (A1) onto Figure A-1 in which the later data recorded for the aluminum-enhanced bubbles are shown. Notice that the linear regression 
analysis plotted for equation (A2) has a somewhat steeper slope. This may result from a nonlinear, second-order relationship between $\mathrm{V}_{\max }$ and $\mathrm{dV} / \mathrm{dt}$, although differences between the growth behavior of the chemically generated bubbles inflated with both hot hydrogen and steam (equation A2) and the nonchemically generated bubbles inflated only with steam (equation A1) cannot be ruled out.

Equation A2 may be applied to the large, partially viewed bubble produced by the underwater combustion of molten aluminum described by Nelson (1995). We see that in his Figure 7, the bubble grew to about $15 \mathrm{~L}$ in $5 \mathrm{~ms}$ before the chamber failed. This gives $\mathrm{dV} / \mathrm{dt}=3000 \mathrm{~L} / \mathrm{s}$. Inserting this value in equation $A 2$, we obtain a $V_{\max }$ of $25 \mathrm{~L}$, which is in reasonable agreement with the $30 \mathrm{~L}$ estimated from $\mathrm{V}_{\max }$ and $\mathrm{dV} / \mathrm{dt}$ of the comparison bubble generated by the high explosive. This suggests that the correlation given in equation A2 may permit extrapolations and interpolations over a fairly large range of bubble volumes. Equation A1 may apply only to bubbles smaller than about a liter. 


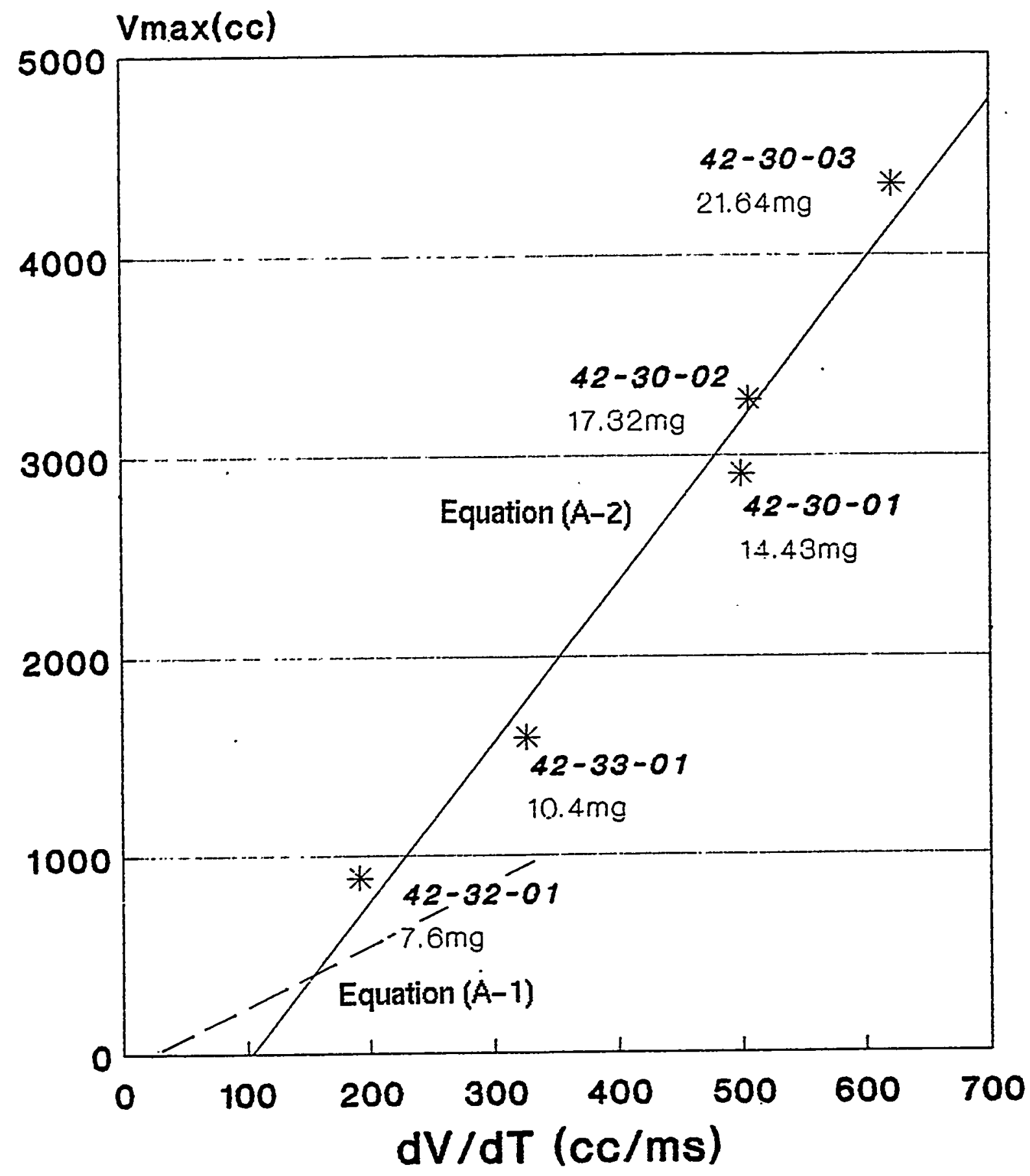

Figure A-1. Maximum bubble volumes plotted against the corresponding slope of the bubble volume-time curve for various bubbles generated by discharging capacitors through underwater aluminum strips. See Table 1 for experimental details. 


\section{References For Appendix A}

Beck, D.F., 1989, Memorandum, D.F. Beck to M. Berman, Underwater Detonator Performance in Triggering Studies, Sandia National Laboratories, Albuquerque, NM.

Nelson, L.S., and Duda, P.M., 1981, Steam Explosion Experiments with Single Drops of Iron Oxide Melted with a $\mathrm{CO}_{2}$ Laser, Sandia National Laboratories, Albuquerque, NM, NUREG/CR2295, SAND81-1346.

Nelson, L.S., and Duda, P.M., 1982, "Steam Explosion Experiments with Single Drops of Iron Oxide Melted with a $\mathrm{CO}_{2}$ Laser," High Temperatures, High Pressures, 14, 259-281.

Nelson, L.S., and Duda, P.M., 1983, "Steam Explosions of a Metallic Melt as its Degree of Exidation Increases: $\mathrm{Fe}, \mathrm{FeO}_{1.0}$, and $\mathrm{FeO}_{1.2}$," Proc. Int'l. Mtg. on Thermal Nuclear Reactor Safety, Aug. 29 - Sept. 2, 1982, Chicago, I, U.S. Nuclear Regulatory Commission, Washington, DC, NUREG/CP0027, Vol. 2, 981-986.

Nelson, L.S., and Duda, P.M., 1985, Steam Explosion Experiments with Single Drops of Iron Oxide Melted with a $\mathrm{CO}_{2}$ Laser, Part II, Parametric Studies, Sandia National Laboratories, Albuquerque, NM, NUREG/CR-2718, SAND82-1105.

Nelson, L.S., Duda, P.M., Hyndman, D.A., Allison, D.K., and Hyder, M.L., 1995, Thermal and Ignition-Type Steam Explosions of Single Drops of Molten Aluminum, Westinghouse Savannah River Company, Aiken, SC, WSRC-RP-95-718.

Nelson, L.S., Fuketa, T., Eatough, M.J., Vigil, F.J., Szklarz, D.D., Wong, C.C., and Hyndman, D.A., 1992, Steam Explosions of Single Drops of Thermite-Generated Melts: 25 and 50 Weight Percent Aluminum-Iron Oxide Initial Mixtures," SAND90-0511, Sandia National Laboratories, Albuquerque, NM.

Nelson, L.S., Hogeland, S.R., and Utash, J.L., 1994, Bubble Growth, Shock Waves and Flow Transients Produced by Underwater Capacitor Discharges, SAND93-0765, Sandia National Laboratories, Albuquerque, NM.

Nelson, L.S., 1995, "Steam Explosions of Single Drops of Pure and Alloyed Molten Aluminum," Nucl. Eng. Des., 155, 413-425. 


\section{Distribution}

1 Patrick T. Rhoads

Office of Engineering \& Program

Management, DP-42

U.S. Department of Energy

Room GA073/Forrestal Building

1000 Independence Ave SW

Washington, DC 20585

1 Patricia R. Worthington

Risk and Policy Analysis Div., NS-20

Office of Nuclear Safety

U.S. Department of Energy

Room D-432/GTN

19901 Germantown Road

Germantown, MD 20585

1 Robert W. Wright

14400 Homecrest Rd.

Apt. 220

Silver Spring, MD 20906

1 Paul S. Shieh

U.S. Department of Energy/SR00

P.O. Box A

Aiken, SC 29802

2 Argonne National Laboratory

Attn: Dae H. Cho Walter Deitrich

RAS, Building 208

9700 South Cass Avenue

Argonne, IL 60439-4842

4 Argonne National Laboratory

Attn: J. J. Sienicki

Bruce Spencer

Tom Y. C. Wei

Arthur E. Wright

RAS, Building 206

9700 South Cass Avenue

Argonne, II 60439-4842
2 Battelle Memorial Institute

Attn: Peter Cybulskis

Richard S. Denning

505 King Avenue

Columbus, $\mathrm{OH} 43201$

2 Brookhaven National Laboratory

Attn: George A. Greene James Guppy

Experimental Heat Transfer and

Fluid Dynamics Group

Department of Nuclear Energy

Building 820M

Upton, NY 11973

1 David A. Ward

David Ward Associates

P.O. Box 6500

North August, SC 29841

1 Jacek Jedruch

Ebasco Services, Inc.

Two World Trade Center $-89^{\text {th }}$ Floor

New York, NY 10048

2 Fauske \& Associates, Inc.

Attn: Michael Epstein

Hans K. Fauske

16 W070 West $83^{\text {rd }}$ Street

Burr Ridge, II 60521

1 Massachusetts Institute of Technology

Attn: Majid Kazimi, Rm. 219

Neil Todreas, Rm. 215

Department of Nuclear Energy

Building 24

77 Massachusetts Avenue

Cambridge, MA 02139

1 Prof. George E. Apostolakis

38-137 Engineering IV

University of California

Los Angeles, CA 90024-1597 
1 Thomas Kress

Oak Ridge National Laboratory

NRC Programs

P.O. Box X, Bldg. 4500 S

Oak Ridge, TN 37831

1 Anthony P. Malinauskas

Oak Ridge National Laboratory

Mail Stop 6135

Building 4500, Room A170

P.O. Box 2008

Oak Ridge, TN 37831-6135

1 Michael Podowski

Department of Nuclear Engineering and Engineering Sciences

Rensselaer Polytechnic Institute

NES Building

Tibbits Avenue

Troy, NY 12180-3590

2 University of California Los Angeles

Attn: Prof. Ivan Catton

Prof. David Okrent

Nuclear Energy Laboratory

405 Hilgard Avenue

Los Angeles, CA 90024

1 Theofanis G. Theofanous

University of California

Department of Chemical and

Nuclear Engineering

Santa Barbara, CA 93106

1 Harold L. Dodd

University of Tennessee

Nuclear Engineering Department

315 Pasqua

Knoxville, TN 37996

1 Prof. Mike L. Corradini

University of Wisconsin

Department of Engineering Physics

1500 Engineering Drive

Madison, WI 53706-1687
10 Lloyd S. Nelson

University of Wisconsin

Department of Engineering Physics

1500 Engineering Drive

Madison, WI 53706-1687

1 M. Lee Hyder

33 Longwood Drive

Aiken, SC 29808

1 Paul R. Monson

Westinghouse Savannah River Company

Building 704-1T

Aiken, SC 29808

1 Jerome P. Morin

Westinghouse Savannah River Company

Building 703- $\mathrm{H}$

Aiken, SC 29808

2 Crispin W. Thiessen, Vice President

Westinghouse Savannah River Company

Building 703-A

Aiken, SC 29808

1 Robert Brodsky

Nuclear Power Technology, Inc.

2018 Turtle Pond Drive

P.O. Box 2969

Reston, VA 22091

1 J. Roger Hilley

HCR 39, Box 136

Willow Springs, MO 65793-9017

1 Henry E. Stone

6805 Castlerock Drive

San Jose, CA 95120

1 Rusi P. Taleyarkhan, Group Leader

Energy Technology Division

Lockheed Martin Energy Research Corp.

P.O. Box 2009, ORNL

Bldg. 9204-1

Oak Ridge, TN 37831-8045 


\begin{tabular}{|c|c|c|}
\hline \multicolumn{3}{|c|}{ INTERNAL DISTRIBUTION: } \\
\hline 1 & MS1380 & M. Berman, 4300 \\
\hline 1 & MS1380 & D. F. Beck, 4315 \\
\hline 1 & MS0425 & D. M. Kunsman, 5415 \\
\hline 1 & MS0425 & A. C. Payne, 5415 \\
\hline 1 & MS0423 & S. E. Dingman, 5417 \\
\hline 1 & MS0759 & C. D. Jaeger, 5845 \\
\hline 1 & MS0736 & T.E. Blejwas, 6400 \\
\hline 1 & MS0744 & D. A. Powers, 6400 \\
\hline 1 & MS0747 & A. L. Camp, 6412 \\
\hline 1 & MS0747 & V. J. Dandini, 6412 \\
\hline 1 & MS0747 & D. W. Whitehead, 6412 \\
\hline 1 & MS0748 & D. B. Mitchell, 6413 \\
\hline 1 & MS0742 & J. E. Kelly, 6414 \\
\hline 1 & MS0739 & K. D. Bergeron, 6421 \\
\hline 1 & MS1139 & K. O. Reil, 6423 \\
\hline 1 & MS1145 & T. R. Schmidt, 6430 \\
\hline 1 & MS1143 & J. S. Philbin, 6433 \\
\hline 1 & MS1136 & P. S. Pickard, 6440 \\
\hline 1 & MS0977 & D. S. Stuart, 6524 \\
\hline 1 & MS0716 & S. E. Slezak, 6805 \\
\hline 1 & MS0834 & T. Y. Chu, 9112 \\
\hline 1 & MS0405 & T. D. Brown, 12333 \\
\hline 1 & MS0405 & M. L. Young, 12333 \\
\hline 1 & MS0899 & Technical Library, 4619 \\
\hline 1 & MS9018 & Central Technical Files, 9040-2 \\
\hline 1 . & MS0619 & $\begin{array}{l}\text { Review \& Approval Desk, } 00111 \\
\text { For DOE/OSTI }\end{array}$ \\
\hline
\end{tabular}

